\title{
Poderia o aleitamento materno reduzir o risco de obesidade em crianças e adolescentes?
}

\author{
Renata Scanferla Siqueira
}

Dissertação apresentada ao Programa de PósGraduação da Faculdade de Saúde Pública da Universidade de São Paulo para obtenção do título de Mestre em Saúde Pública.

Área de concentração: Nutrição

Orientador: Prof. Dr. Carlos Augusto Monteiro.

São Paulo

2005

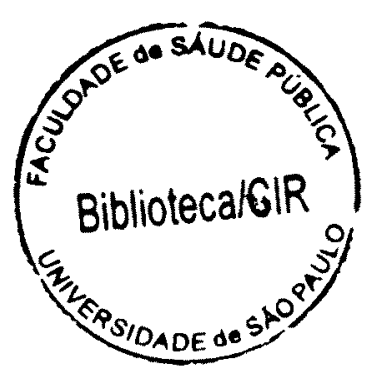


Dedico este trabalho a João Borges.

Sem o seu amor, apoio e incentivo constante, esta conquista seria apenas um sonho. 


\section{Agradecimentos especiais}

Aos meus avós, Doralina e Waldir (in memoriam), pelo seu amor incondicional e pela minha educação.

Aos meus pais, pela minha vida e minha história. Em especial, à minha mãe, grande companheira e amiga, por seu exemplo de amor, coragem, determinação e força.

À Dri e Celinho, amigos de todas as horas. 


\section{Agradecimentos}

Ao professor Carlos Augusto Monteiro, por sua visão ampla e inteligente, sólidos conhecimentos e pela confiança depositada fazendo desta orientação um grande aprendizado para mim.

Aos professores, Maria Pastor e Armando Pires, pelo imprescindivel apoio e incentivo quando decidi dar os "primeiros passos" em direção a esta conquista.

Ao professor Wolney Conde, por todo o apoio dado ao longo deste trabalho, principalmente, pela fundamental ajuda no decorrer das análises estatísticas.

Às professoras Maria Helena Benício e Inês Rugani, pelo carinho e pelas valiosas sugestões dadas a este trabalho.

À professora Maria do Rosário Latorre, pela excelente disciplina "Regressão Logística" e pelo apoio dado a este trabalho.

À Luiza Pimentel, pelo seu imenso carinho e fundamental ajuda em momentos importantes do desenvolvimento deste trabalho.

À Regina Rodrigues pela ajuda na elaboração do questionário.

Ao Edson Faulin, pelo carinho com que me ensinou a trabalhar como programa Epidata na digitação do meu banco de dados.

A toda equipe da escola onde realizei o trabalho de campo pelo carinho com que me receberam, em especial, à nutricionista Irene Coutinho e ao professor Rafael Zamana.

A todos os alunos e mães que participaram deste estudo.

Por fim, ao CNPq, pela bolsa de estudos concedida. 


\section{Resumo}

Siqueira, RS. Poderia o aleitamento materno reduzir o risco de obesidade em crianças e adolescentes? São Paulo, 2005 [Dissertação de mestrado-Faculdade de Saúde Pública - Universidade de São Paulo].

Contexto: A obesidade é considerada uma epidemia global e sua prevalência em crianças e adolescentes vem aumentando nas últimas décadas não só nos países desenvolvidos mas também nos que estão em desenvolvimento. Em crianças e adolescentes, a obesidade está associada a fatores de risco para doenças cardiovasculares, respiratórias e metabólicas, além de contribuir para a baixa auto-estima e discriminação social, oportunizando, assim, complicações emocionais. A obesidade em crianças constitui-se, ainda, em fator preditivo para a obesidade no adulto. Seu tratamento é difícil e, muitas vezes, sem sucesso, tornando fundamental sua prevenção. Estudos epidemiológicos sugerem que o aleitamento materno na infância pode atuar como fator protetor contra obesidade na infância e adolescência. Objetivo: examinar a associação entre aleitamento materno na infância e a ocorrência de obesidade em crianças e adolescentes brasileiros com idades entre 6 e 14 anos.Métodos: estudo transversal envolvendo 555 crianças e adolescentes brasileiros com idades entre 6 e 14 anos, estudantes de uma escola particular localizada na zona sul da cidade de São Paulo. A primeira etapa do estudo consistiu na tomada de medidas de peso, altura e dobras cutâneas (tricipital e subscapular). As medidas de dobras cutâneas foram tomadas duas vezes pelo mesmo indivíduo. A segunda etapa do estudo envolveu o preenchimento, pelas mães dos alunos, de um questionário estruturado.A obesidade - variável desfecho do estudo - foi definida como IMC $\geq$ percentil 85 aliado a valores de pregas cutâneas $\geq$ percentil 90 , em ambos os casos adotando-se como referência o padrão NCHS/OMS. A variável exposição foi a freqüência e a duração do aleitamento materno. Resultados: a prevalência de obesidade foi de $26 \%$. O presente estudo sugere que o risco de obesidade em crianças e adolescentes que nunca receberam aleitamento materno é duas vezes superior $(\mathrm{OR}=2,06$; IC $95 \% 1,02$ 4,16 ) ao risco nos demais. Não se encontrou um efeito dose-resposta na associação entre duração do aleitamento e obesidade na infância e adolescência. Conclusão: crianças e adolescentes que nunca receberam aleitamento materno têm maior risco de obesidade sem e com ajuste para variáveis de confusão e empregando-se, no caso de análises ajustadas, a regressão logística. Entretanto, são necessários mais estudos, principalmente estudos longitudinais, para melhor esclarecer a associação entre a duração do aleitamento materno e a obesidade em crianças e adolescentes.

Descritores: aleitamento materno, obesidade, crianças, adolescentes. 


\section{Summary}

Siqueira, RS. Does breast-feeding reduce the risk of obesity in children and adolescents?Poderia o aleitamento materno reduzir o risco de obesidade em crianças e adolescentes? São Paulo, 2005 [Master's degree dissertation- School of Public Health - University of São Paulo].

Context: Obesity is considered a global epidemic and its prevalence in children and adolescents have been rising over the past two decades not only in developed countries but also in developing ones. Children obesity is associated with cardiovascular, respiratory and metabolic diseases and also obesity contributes to lower self-steem and adverse social and emotional outcomes. Also child obesity predicts obesity in later life. Once present, obesity is hard to treat. For this reason, prevention is a paramout. Epidemiologic studies suggest that breast-feeding can protect against obesity in children and adolescents. Objetive: to examine the association between breast-feeding and obesity in Brazilians students aged 6 to 14 years old. Métodos: cross-sectional study. The sample consisted of 555 students aged 6 o 14 years from a private school situated in city of São Paulo. In the first part of the study, body weight, height, subscapular and triciptal skinfolds were measured. A single anthropometrist carried out each skinfold measure on all participants. In the second part of the study, a structured questionnaire was filled out by the student's mothers. Obesity was defined as body mass index (BMI) at or above the $85^{\text {th }}$ centile of sex and age specific distribution plus subscapular and tricipts skinfold at or above the 90th centile (NCHS/WHO). Results: the prevalence of obesity was $26 \%$. This study suggests that the risk of obesity in children and adolescents that have never been breast-fed doubled compared with those breast-fed $(\mathrm{OR}=2,06$; IC95\% 1,02-4,16). There was no dose-dependent effect of the duration of breast-feeding on the prevalence of obesity. Conclusion: children and adolescents never breast-fed have greater risk of obesity, even after adjusting for potential confouding factors. We used logistic regression to adjust for confouding.This find indicates that further studies, mainly longitudinal ones, are needed to better explain the association between breast-feeding and obesity in children and adolescents.

Descriptors: breast-feeding, obesity, children, adolescents. 


\section{ÍNDICE}

1. INTRODUÇÃO ..........................................................................................................2

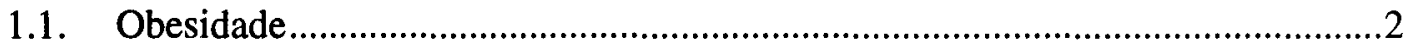

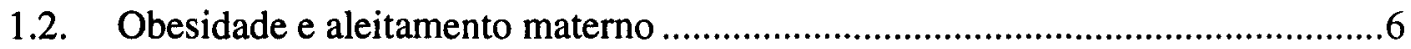

1.3. Possíveis mecanismos subjacentes à associação entre aleitamento materno e risco para obesidade e sobrepeso na infância e adolescência ............................14

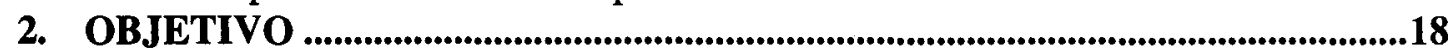

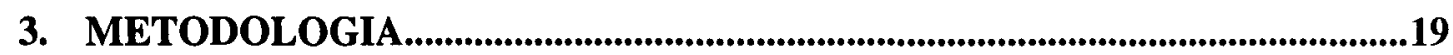

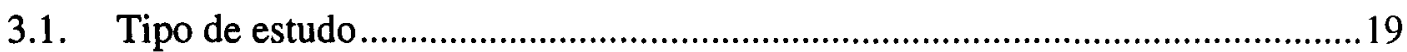

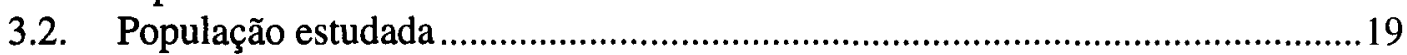

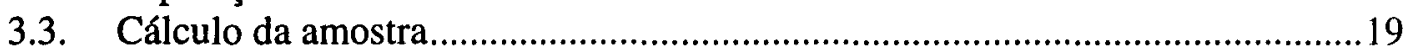

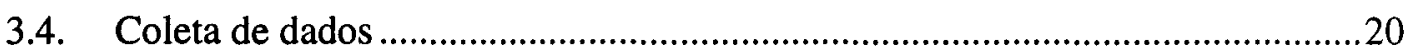

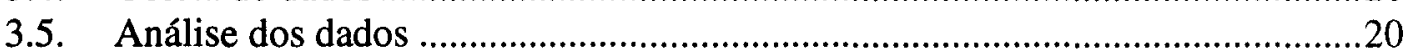

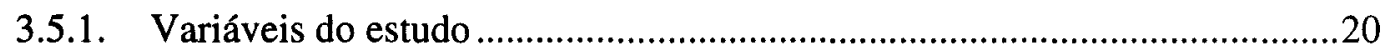

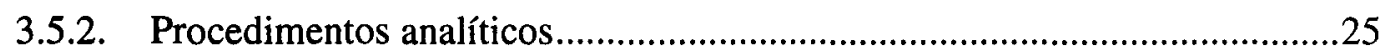

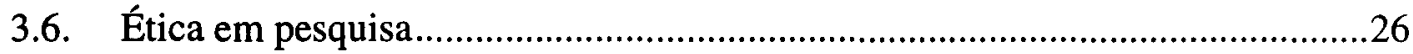

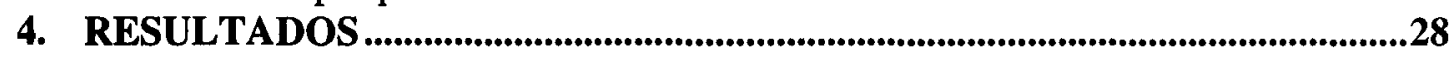

4.1. Caracterização da população de estudo ..........................................................28

4.2. Associação entre aleitamento materno e obesidade: análise bivariada...............33

4.3. Associação entre aleitamento materno e obesidade: análise multivariada ........37

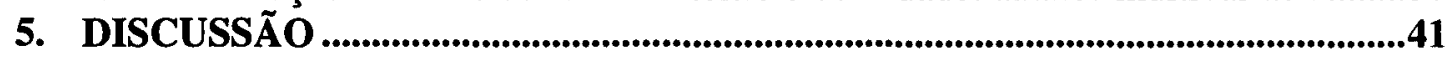

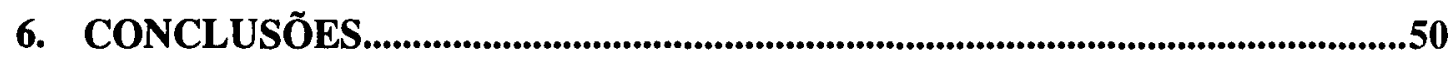

7. REFERÊNCIAS BIBLIOGRÁFICAS …...........................................................51 


\section{INTRODUÇÃO}

\subsection{Obesidade}

A obesidade, de forma simplificada, é conseqüência de um desequilíbrio energético no qual o consumo excede as necessidades energéticas do organismo durante um considerável período, levando ao acúmulo excessivo de tecido adiposo. Diversos fatores podem levar a um balanço energético positivo, porém se sabe que é a interação de múltiplos fatores - e não um único fator - o que provoca a obesidade.

Estudos epidemiológicos sugerem que fatores ambientais e comportamentais contribuíram fundamentalmente para a epidemia global da obesidade (WHO, 2003). O aumento das prevalências de obesidade em um curto período de tempo descarta a possibilidade de que fatores genéticos per si tenham provocado essa recente epidemia.

Por um lado, a obesidade está particularmente relacionada ao consumo de alimentos com alta densidade energética e, por outro lado, ao sedentarismo, que resultou da crescente urbanização e mecanização ocorridas em diversas sociedades. Destaca-se a transição nutricional decorrente das mudanças nos padrões nutricionais ao longo do tempo, convergindo para a chamada "dieta ocidental": rica em gorduras, açúcares e alimentos refinados e, ao mesmo tempo, pobre em fibras e carboidratos complexos. (WHO, 2003; Monteiro, 2000; Popkin, 2002).

Diferentemente da população adulta, não há consenso sobre critérios mais adequados para classificar como obesos crianças e adolescentes. Usualmente são 
utilizados percentis de curvas de distribuição do IMC segundo idade e sexo, empregando-se como nível crítico para o diagnóstico da obesidade o percentil 85 do IMC aliado a valores das pregas cutâneas tricipital e subescapular maiores ou iguais ao percentil 90 (NCHS/OMS, 1995).

As consequiências da obesidade são diversas e representam importante impacto no perfil de morbi-mortalidade de diversas sociedades. A obesidade em crianças e adolescentes, além de estar associada ao risco de obesidade na vida adulta, provoca sérios efeitos adversos à saúde tanto no decorrer desses períodos da vida como em idades posteriores.

Dentre as conseqüências imediatas da obesidade em crianças e adolescentes, destacam-se alterações psicológicas, cardiovasculares, respiratórias, hormonais, além da marginalização social.

Reilly et al (2003) concluíram que crianças obesas estão mais susceptíveis a distúrbios psicológicos e psiquiátricos em relação às não obesas e que o risco de apresentar esses distúrbios aumenta com a idade. Também evidenciaram que a baixa auto-estima e problemas comportamentais são comumente associados à obesidade, fato este também documentado em revisão realizada por French et al (1995).

Strauss (2003), estudando adolescentes americanos de 13 a 18 anos, concluiu que - comparados aos que estavam com peso adequado - aqueles que estavam com sobrepeso ou obesidade eram mais isolados socialmente e menos escolhidos como 
amigos. Dessa forma, adolescentes com sobrepeso eram os menos populares do grupo e os que menos participavam de atividades sociais.

As complicações cardiovasculares estão fortemente associadas à obesidade na infância e adolescência. Freedman (1999), Ronnemma (1991) e Smoak (1987) relatam, ainda alterações significativas na pressão sistólica e diastólica, mudanças nos níveis de colesterol plasmático com aumento do LDL (lipoproteínas de baixa densidade) e redução do HDL (lipoproteínas de alta densidade), aumento na concentração plasmática de triglicerídeos e aumento na concentração plasmática da insulina pós-prandial.

A partir de análise de inquéritos populacionais americanos (NHES 19631995,1966-1970; NHANES 1971-1974, 1976-1980), Gortmaker $e$ col. (1987) relataram que a obesidade é uma das principais causas da hipertensão arterial em crianças. Estudo de Macedo (1997) reforça a associação entre hipertensão arterial em crianças e adolescentes portugueses e a ocorrência de obesidade.

Em conseqüência da obesidade, podem ocorrer alterações da função respiratória. Reilly et al (2003) detectaram fortes evidências de que a asma é uma importante comorbidade da obesidade em crianças e adolescentes. Outras alterações respiratórias associadas à obesidade são hipoventilação e apnéia do sono (Mallory,1989; Riley,1976).

Evidências epidemiológicas indicam que o diabetes tipo 2, que até recentemente era considerado um distúrbio presente apenas em adultos, está sendo cada vez mais diagnosticado em crianças e adolescentes. $O$ aumento da incidência deste tipo de diabetes coincide com a recente epidemia global da obesidade que já atinge crianças e 
adolescentes em proporções preocupantes (American Diabetes Association, 2000; Aye, 2003; Kahn, 2000; Martin, 1973; Pinhas Ramiel, 1996; Rossembloom, 1999; Steinberger, 1995).

O diabetes tipo 1, de etiologia auto-imune, era o mais comum em crianças e adolescentes até a recente epidemia do diabetes tipo 2. Hypponen e col. (2000) concluíram que a obesidade infantil também está associada a duas vezes o risco para o desenvolvimento de diabetes tipo 1 .

Quando se trata da obesidade na infância e adolescência, não se pode deixar de chamar atenção para as conseqüências desta doença a longo prazo, pois ela está fortemente associada à obesidade na vida adulta (Power 1997; Serdula, 1993, Whitaker, 1997).

Considerando-se o atual perfil de morbi-mortalidade adulta de diversas sociedades, desenvolvidas ou em desenvolvimento, nas quais se evidencia aumento das doenças crônicas não transmissíveis e, sendo a obesidade um importante fator de risco para muitas destas doenças, pode-se perceber a importância desta doença.

No Brasil, dados da Pesquisa sobre Padrões de Vida, realizada pelo IBGE entre 1996 e 1997 indicam que a prevalência do excesso de peso em indivíduos com idades entre 6 e 18 anos residentes nas regiões Nordeste e Sudeste era em torno de $14 \%$ Comparando-se este valor à prevalência do problema em 1974 - 4,9\% em crianças de 6 a 9 anos e $3,7 \%$ em adolescentes de 10 a 18 anos - verifica-se o aumento alarmante de 
sobrepeso e obesidade nas duas últimas décadas e, conseqüentemente, prognostica-se um alto impacto negativo para a Saúde Pública (Monteiro, 2002).

\subsection{Obesidade e aleitamento materno}

Alguns estudos epidemiológicos sugerem que o aleitamento materno pode atuar como fator protetor contra o desenvolvimento de sobrepeso e obesidade em crianças e adolescentes, proteção esta reconhecida pela Organização Mundial de Saúde (WHO, 2003).

Em uma revisão que fizemos de artigos publicados sobre a associação entre áleitamento materno e obesidade em crianças e adolescentes com idades entre 3 e 18 anos, notamos inicialmente uma imensa variação entre os estudos com relação à definição do aleitamento e da obesidade, à faixa etária, aos procedimentos para coleta de dados, ao tamanho da amostra e ao controle de variáveis de confusão. Dos doze estudos revistos que se referiam a crianças maiores de 3 anos e adolescentes (quadro 1), sete encontraram associação significativa inversa entre o aleitamento materno na infância e a obesidade e, dentre esses, quatro $(1,4,5,7)$ encontraram efeito dose-resposta significativo na associação.

A existência de resultados contraditórios nos estudos que avaliaram a associação entre aleitamento materno e obesidade poderia decorrer de diferenças entre os estudos quanto ao tamanho da amostra, delineamento e controle de variáveis de confusão.

No que diz respeito ao tamanho da amostra, dentre os estudos com grandes amostras $(>500)$, sete encontraram associação significativa entre o aleitamento materno 
na infância e o sobrepeso e obesidade $(1,4,5,6,7,8,9)$ e três não encontraram $(10,11,12)$. Ressalta-se que Victora (12), apesar de ter encontrado uma redução de 50\% no risco de obesidade para os que receberam aleitamento total por 3 a 5 meses comparados as demais categorias e uma tendência linear para redução da obesidade com o aumento da duração do aleitamento materno predominante, não considerou consistentes os resultados de seu estudo. Quanto aos estudos com grandes amostras que não encontraram resultados significativos no efeito protetor do aleitamento materno contra o sobrepeso e obesidade vale notar que: Li et al (10) avaliaram indivíduos com idades entre 4 e 18 anos, Parsons et al (11) avaliaram indivíduos aos 7 e 33 anos de idade e Victora (12), em seu estudo longitudinal, avaliou somente jovens do sexo masculino com 18 anos de idade. Os dois estudos realizados com amostras menores, não encontram associação significativa na relação entre aleitamento materno e risco de sobrepeso e obesidade $(2,3)$.

Em relação ao delineamento do estudo, dos doze estudos revistos, somente dois eram prospectivos $(9,12)$. O estudo de Victora (12), conforme já mencionado, não encontrou associações consistentes na relação entre a duração do aleitamento materno total e predominante e obesidade e o estudo longitudinal de Bergmann (2003), que incluiu crianças com até 6 anos de idade, encontrou uma redução estatisticamente significativa no risco de sobrepeso e obesidade em crianças que receberam aleitamento materno por pelo menos 3 meses.

Quanto aos estudos retrospectivos, ressalta-se que os mesmos dependem da memória da mãe, o que poderia levar a viéses, apesar de alguns estudos já terem 
indicado a acurácia e validade das informações retrospectivas sobre aleitamento materno fornecidas pela mãe (Kark, 1984; Haaga, 1988; Launer, 1992 ). A amplitude da faixa etária dos estudos pode ser um fator importante ao coletar informações retrospectivas sobre o aleitamento materno. Estudos que avaliaram a variável de exposição (aleitamento materno) e a variável desfecho (obesidade) em crianças mais novas têm menor chance de viéses devido à memória da mãe quando comparados àqueles que incluíram adolescentes, por exemplo.

Por último, é importante ressaltar o controle das variáveis de confusão, particularmente peso ao nascer, nível socioeconômico e obesidade materna. Dos estudos revistos, todos controlaram peso ao nascer e nível socioeconômico.

A forma de definir o nível socioeconômico variou entre os estudos. Alguns estudos basearam-se na ocupação paterna ou do chefe de família $(3,6,10)$, outros na renda média familiar $(5,12)$ e na escolaridade $(4,8)$. Vale notar que o estudo de Toschke (8) foi realizado na ex Tchecoslováquia, sociedade socialista na época, onde se supõe que as variações quanto ao nível socioeconômico eram menores, em outras palavras, as condições de vida das famílias eram mais homogêneas.

O IMC materno - que apresentou forte associação com a adiposidade infantil nos estudos de Bergmann (9), Hediger (6), Kramer (1), Zive (2) e Gilmann (5)- não foi avaliado por Elliot (3), Liese (7), Victora (12) e Von Kries (4). Dentre os estudos que não avaliaram o IMC materno, dois encontraram associação significativa entre o aleitamento materno na infância e a obesidade $(4,7)$ e dois não encontraram $(3,12)$. 
Ressalta-se que o estudo de Li et al (10) controlou o IMC do pai ou da mãe, ou seja, somente de um membro da família. A associação entre o IMC materno e a obesidade na criança e no adolescente sugere influência genética e comportamental no desenvolvimento desta patologia (Bergmann, 2003; Charney, 1976; Gillman, 2001; Hediger, 2001; Kramer,1981; Toschke, 2002).

O padrão alimentar, a atividade física e a quantidade de horas diárias vendo televisão foram variáveis que também se mostraram relacionadas à obesidade na adolescência em outros estudos (Kelder, 1994; Proctor, 2003).

Dentre os estudos que encontraram associação significativa entre aleitamento materno e obesidade, Toschke (2002) e Gilmann (2001) avaliaram o efeito da atividade física e o tempo da criança diante da televisão. Toschke (2002) também avaliou o consumo de frutas por dia e concluiu que as crianças que foram alimentadas com leite industrializado viam televisão durante mais horas por dia e comiam menor quantidade de frutas do que aquelas crianças que receberam aleitamento materno. Von Kries (1999) avaliou o padrão alimentar para determinados grupos de alimentos e atividades de lazer no verão e no inverno.

A classificação de categorias do aleitamento materno também pode ser mais um motivo para os resultados contraditórios: apenas três estudos $(4,6,7)$ distinguiram o aleitamento exclusivo e ainda assim de forma variada. Além da definição do aleitamento materno, os estudos variaram quanto à classificação de sua duração. Como podemos observar no quadro 1, Kramer (1) não classifica a duração do aleitamento materno, ou 
seja, considera apenas se a criança recebeu ou não leite materno. Elliot (3) considera o aleitamento durante um período 2 meses ou mais ou menor que 2 meses. Parsons (11) utilizou como ponto de corte 1 mês de duração enquanto outros autores utilizam outros pontos de corte.

Outro fator importante de variação entre os estudos é a definição da obesidade em crianças e adolescentes. Kramer (1) utilizou peso relativo maior ou igual a $120 \%$ aliado a valores de pregas cutâneas acima do percentil 90 , ambos conforme padrão de referencia NCHS/1973; Li e Parsons $(10,11)$ utilizaram valores de IMC acima do percentil 95 do padrão de referência britânico (1990); Von Kries (4), Toschke (8), Bergmamm (9) utilizaram valores de IMC acima do percentil 97 de acordo com os padrões de referência interno; Victora (12) utilizou como referência a classificação proposta pela OMS (1995), considerando como obesos crianças e adolescentes com IMC acima do percentil 85 aliado a valores de pregas cutâneas (tricipital e subescapular) acima do percentil 90, ambos de acordo com o padrão de referência NCHS/OMS, 1995.

Finalizando, pode-se observar, através da análise dos artigos revistos, que mais estudos são necessários para melhor esclarecer a associação entre o aleitamento materno e a obesidade. 
Quadro 1- Estudos sobre aleitamento materno e sobrepeso e ou obesidade

\begin{tabular}{|c|c|c|c|c|c|}
\hline $\begin{array}{c}\text { Autor/ } \\
\text { ano/local }\end{array}$ & $\begin{array}{l}\text { Método/ tipo } \\
\text { de estudo }\end{array}$ & $\mathrm{N} /$ idade & $\begin{array}{c}\text { Variáveis/definição } \\
\text { sobrepeso/ } \\
\text { obesidade }\end{array}$ & $\begin{array}{c}\text { Definicao } \\
\text { AM }\end{array}$ & $\begin{array}{c}\text { Técnica } \\
\text { estatística/resultados }\end{array}$ \\
\hline $\begin{array}{l}1 \text {-Kramer } \\
\text { MS et al; } \\
\text { 1981; } \\
\text { Canadá }\end{array}$ & $\begin{array}{l}\text { Retrospectivo } \\
\text { Caso controle } \\
1980\end{array}$ & $\begin{array}{l}\mathrm{n}=639 \\
\text { (clinica)+ } \\
533 \\
\text { (escola) } \\
12 \text { a } 18 \\
\text { anos }\end{array}$ & $\begin{array}{l}\text { Peso ao nascer; ordem } \\
\text { nascimento; peso atual; } \\
\text { ganho de peso; pregas } \\
\text { tricipitais e subescapular; } \\
\text { etnia; classe } \\
\text { socioeconômica; idade, } \\
\text { estado nutricional dos } \\
\text { pais; introdução de } \\
\text { alimentos sólidos; } \\
\text { aleitamento. } \\
\text { Obesidade: peso relativo } \\
\text { >120\% pregas>percentil } \\
\mathbf{9 0}\end{array}$ & $\begin{array}{l}\text { AM } \\
\text { (sim e não e } \\
\text { duração) } \\
\text { *Até 1 } \\
\text { mamadeira } \\
\text { por dia } \\
\text { considerava } \\
\text { AM }\end{array}$ & $\begin{array}{l}\checkmark \text { Estratificação } \\
\checkmark \text { ORbruto=2,25 } \\
\text { IC 95\%:(1.07-4.73). } \\
\checkmark \text { Não cita OR ajustado, } \\
\text { mas afirma que continua } \\
\text { significativo. } \\
\checkmark \text { Variáveis de confusão: } \\
\text { história familiar de } \\
\text { obesidade, classe sócio } \\
\text { econômica e ordem de } \\
\text { nascimento. } \\
\checkmark \text { Efeito dose dependente } \\
\text { na duração do } \\
\text { aleitamento e prevalência } \\
\text { de obesidade. }\end{array}$ \\
\hline $\begin{array}{l}\text { 2- Zive et } \\
\text { al. } 1992, \\
\text { EUA }\end{array}$ & $\begin{array}{l}\text { Retrospectivo } \\
\text { Transversal }\end{array}$ & $\begin{array}{l}n=331 \\
4 \text { anos }\end{array}$ & $\begin{array}{l}\text { Sexo,; peso ao nascer; } \\
\text { idade; peso; altura; pregas } \\
\text { cutâneas (tricipital e } \\
\text { suscapular); etnia; } \\
\text { aleitamento; introdução } \\
\text { de sólidos; consumo } \\
\text { alimentar (recordatório } \\
24 \text { h); escolaridade, IMC } \\
\text { e pregas cutâneas da mãe; } \\
\text { estado civil; classe sócio- } \\
\text { econômica. } \\
\text { * não indicou ponto de } \\
\text { corte usado p/ definir } \\
\text { obesidade. }\end{array}$ & $\begin{array}{l}\text { NAM } \\
\text { AM: }<1 \\
\text { semana a } \\
>12 \text { meses }\end{array}$ & $\begin{array}{l}\checkmark \text { Regressão linear } \\
\checkmark \mathrm{r}^{2}=0,16 \\
\checkmark \text { Não encontrou } \\
\text { associação significativa }\end{array}$ \\
\hline $\begin{array}{l}\text { 3- Elliot KG } \\
\text { et al, 1997, } \\
\text { EUA } \\
\end{array}$ & $\begin{array}{l}\text { Retrospectivo } \\
\text { Transversal } \\
1977-1980\end{array}$ & $\begin{array}{l}\mathrm{n}=136 \\
\text { (adolescen } \\
\text { tes/grau } \\
10)\end{array}$ & $\begin{array}{l}\text { Sexo; peso ao nascer,; } \\
\text { idade gestacional; IMC; } \\
\text { classe socioeconômica. } \\
\text { Obesidade IMC } \geq \\
\text { percentil } 85\end{array}$ & $\begin{array}{l}\text { NAM ou } \\
\text { AM } \\
<2 \text { meses } \\
\text { AM } \\
>2 \text { meses }\end{array}$ & $\begin{array}{l}\checkmark \text { Análise independente: } \\
\text { OR=2,4 } \\
\checkmark \text { Regressão logística } \\
\text { múltipla: não encontrou } \\
\text { associação significativa } \\
\checkmark \text { Variáveis de ajuste: sexo, } \\
\text { peso ao nascer; nível } \\
\text { socioeconômico. }\end{array}$ \\
\hline $\begin{array}{l}\text { 4-Von Kries } \\
\text { et al; } 1999 ; \\
\text { Alemanha. }\end{array}$ & $\begin{array}{l}\text { Retrospectivo } \\
\text { Transversal } \\
1997\end{array}$ & $\begin{array}{l}\mathrm{n}=9357 \\
5 \text { a } 6 \text { anos }\end{array}$ & $\begin{array}{l}\text { Idade gestacional; peso ao } \\
\text { nascer; introdução } \\
\text { alimentar; peso e altura } \\
\text { atuais; escolaridade } \\
\text { (proxy classe social); } \\
\text { padrão alimentar; estilo } \\
\text { de vida familiar } \\
\text { (tabagismo materno, } \\
\text { idade pais, tempo gasto } \\
\text { em atividades fora de casa } \\
\text { no verão e inverno, etc) } \\
\text { Sobrepeso- IMC > } \\
\text { percentil 90 } \\
\text { Obesidade - IMC > } \\
\text { percentil } 97\end{array}$ & $\begin{array}{l}\text { NAM } \\
\text { AME: } \leq 2 \\
\text { meses; } 3 \text { a } 5 \\
\text { meses; } 6 \text { a } \\
12 \text { meses; } \\
>1 \text { ano }\end{array}$ & $\begin{array}{l}\text { Regressão logística } \\
\text { múltipla } \\
\checkmark \text { Variáveis de ajuste: } \\
\text { escolaridade pais; fumo } \\
\text { materno na gravidez; } \\
\text { peso ao nascer; consumo } \\
\text { semanal manteiga; cama } \\
\text { própria. } \\
\checkmark \text { Variável de confusão: } \\
\text { escolaridade pais } \\
\checkmark \text { Efeito dose dependente } \\
\text { na duração do } \\
\text { aleitamento e prevalência } \\
\text { de sobrepeso e obesidade. } \\
\checkmark \text { Sobrepeso: OR=0,79 }\end{array}$ \\
\hline
\end{tabular}




\begin{tabular}{|c|c|c|c|c|c|}
\hline $\begin{array}{c}\text { Autor/ } \\
\text { ano/local }\end{array}$ & $\begin{array}{l}\text { Método/ tipo } \\
\text { de estudo }\end{array}$ & $\mathrm{N} /$ idade & $\begin{array}{c}\text { Variáveis/definição } \\
\text { sobrepeso/ } \\
\text { obesidade }\end{array}$ & $\begin{array}{c}\text { Definicao } \\
\text { AM }\end{array}$ & $\begin{array}{c}\text { Técnica } \\
\text { estatística/resultados }\end{array}$ \\
\hline & & & & & $\begin{array}{l}\text { IC } 95 \%(0,68-0,93) \\
\checkmark \text { Obesidade: OR=0,75 } \\
\text { IC } 95 \%(0,57-0,98) \\
\checkmark 6 \text { meses de AM: redução } \\
\text { do risco de obesidade e } \\
\text { sobrepeso de } 30 \% \text { e } 40 \% \\
\text { respectivamente. }\end{array}$ \\
\hline $\begin{array}{l}\text { 5-Gillman } \\
\text { MW et al; } \\
\text { 2001; EUA. }\end{array}$ & $\begin{array}{l}\text { Retrospectivo } \\
\text { Transversal } \\
\text { (Nurse Health } \\
\text { Study II) }\end{array}$ & $\begin{array}{l}\mathrm{n}=8186 \\
\text { meninas } \\
+7155 \\
\text { meninos } \\
9 \text { a } 14 \\
\text { anos }\end{array}$ & $\begin{array}{l}\text { Idade; sexo; raça; peso; } \\
\text { altura; maturidade sexual } \\
\text { (escala de Tunner); dieta; } \\
\text { atividade física nos } \\
\text { últimos } 12 \text { meses; horas } \\
\text { assistindo TV; peso e } \\
\text { comprimento ao nascer; } \\
\text { idade gestacional; } \\
\text { aleitamento; introdução } \\
\text { de alimentos sólidos } \\
\text { (idade); IMC materno; } \\
\text { tabagismo materno; estilo } \\
\text { de vida materno (dieta, } \\
\text { restrições alimentares, } \\
\text { atividade física, alteração } \\
\text { peso); classe } \\
\text { socioeconômica (censo p/ } \\
\text { renda média familiar) } \\
\text { Risco p/ sobrepeso IMC } \\
\text { entre percentil } 85 \text { e 95 } \\
\text { Sobrepeso - } \\
\text { IMC>percentil 90 }\end{array}$ & $\begin{array}{l}\text { AM } \\
\text { AMP } \\
\text { Duração: } 1^{\circ} \\
6 \text { meses }\end{array}$ & $\begin{array}{l}\text { Regressão logística } \\
\text { múltipla } \\
\checkmark \text { Variáveis de ajuste: } \\
\text { idade; sexo; maturidade } \\
\text { sexual; atividade física; } \\
\text { horas assistindo } \\
\text { televisão; ingestão } \\
\text { calórica; IMC materno e } \\
\text { classe socioeconômica. } \\
\checkmark \text { Sobrepeso: OR=0,78 } \\
\text { IC 95\% (0,66-0,91) } \\
\checkmark \text { Efeito dose dependente }\end{array}$ \\
\hline $\begin{array}{l}\text { 6- Hediger } \\
\text { ML et al; } \\
\text { 2001, EUA. }\end{array}$ & $\begin{array}{l}\text { Retrospectivo } \\
\text { Transversal } \\
\text { NHANES III } \\
1988-1994\end{array}$ & $\begin{array}{l}\mathrm{n}=2685 \\
3 \text { a } 5 \text { anos }\end{array}$ & $\begin{array}{l}\text { Sexo; raça; ordem } \\
\text { nascimento, peso nascer; } \\
\text { peso e altura atuais, idade } \\
\text { gestacional; escolaridade } \\
\text { do chefe família; idade e } \\
\text { IMC materno; tabagismo } \\
\text { gravidez; pré natal } \\
\text { (sim/não); aleitamento, } \\
\text { introdução de alimentos } \\
\text { sólidos } \\
\text { IMC entre } 85 \text { e 94th } \\
\text { =risco de sobrepeso e } \\
\geq 95 \text { th =sobrepeso }\end{array}$ & $\begin{array}{l}\text { NAM } \\
\text { AM } \\
\text { (leite } \\
\text { materno + } \\
\text { água) = } \leq 2 \\
\text { meses; } 3 \text { a } 5 \\
\text { meses; } 6 \text { a } 8 \\
\text { meses; } \\
\geq 9 \text { meses }\end{array}$ & $\begin{array}{l}\checkmark \text { Regressão logística } \\
\text { múltipla } \\
\checkmark \text { Variáveis de ajuste: sexo; } \\
\text { raça; idade; IMC } \\
\text { materno; idade da } \\
\text { introdução de alimentos } \\
\text { sólidos } \\
\checkmark \text { Risco de sobrepeso: } \\
\text { OR=0.63 IC 95\% (0.41- } \\
0.96) \\
\checkmark \text { Sobrepeso: OR=0.84 } \\
\text { IC } 95 \%(0.62-1.13)\end{array}$ \\
\hline $\begin{array}{l}\text { 7- Liese AD } \\
\text { et al, 2001; } \\
\text { Alemanha. }\end{array}$ & $\begin{array}{l}\text { Retrospectivo } \\
\text { Transversal } \\
1995-1996\end{array}$ & $\begin{array}{l}\mathrm{n}=2108 \\
9 \text { a } 10 \\
\text { anos }\end{array}$ & $\begin{array}{l}\text { Peso e altura atuais; } \\
\text { aleitamento; hábito } \\
\text { alimentar atual; peso ao } \\
\text { nascer; idade gestacional; } \\
\text { ordem nascimento; } \\
\text { gêmeos ou não; idade } \\
\text { pais; nacionalidade, classe } \\
\text { sócio-econômica } \\
\text { (escolaridade); tabagismo. } \\
\text { Sobrepeso IMC } \\
\text { percentil } \geq 90\end{array}$ & $\begin{array}{l}\text { AM (sim/ } \\
\text { não)= } \\
\leq 6 \text { meses; } \\
\text { entre } 6 \text { e } 12 \\
\text { meses; >12 } \\
\text { meses } \\
\text { AME } \\
\text { (Inclui água } \\
\text { e chá)= } \\
2 \text { meses; } 2 \text { a } \\
4 \text { meses; } 5 \text { a } \\
6 \text { meses; >6 } \\
\text { meses } \\
\text { NAM }\end{array}$ & $\begin{array}{l}\checkmark \text { Regressão logística } \\
\text { múltipla } \\
\checkmark \text { OR=0,55 IC } 95 \%(0,41- \\
0,74) \text {, ajustando p/ sexo, } \\
\text { idade e cidade. } \\
\checkmark \text { OR=0,66 IC } 95 \%(0,52- \\
0,87) \text { adicionando ajuste } \\
\text { para classe } \\
\text { socioeconômica, } \\
\text { nacionalidade; n }{ }^{\circ} \text { de } \\
\text { irmãos e tabagismo } \\
\text { materno. } \\
\checkmark \text { Efeito dose dependente }\end{array}$ \\
\hline
\end{tabular}




\begin{tabular}{|c|c|c|c|c|c|}
\hline $\begin{array}{c}\text { Autor/ } \\
\text { ano/local }\end{array}$ & $\begin{array}{c}\text { Método/ tipo } \\
\text { de estudo }\end{array}$ & $\mathrm{N} /$ idade & $\begin{array}{c}\text { Variáveis/definição } \\
\text { sobrepeso/ } \\
\text { obesidade }\end{array}$ & $\begin{array}{c}\text { Definicao } \\
\text { AM }\end{array}$ & $\begin{array}{c}\text { Técnica } \\
\text { estatística/resultados }\end{array}$ \\
\hline $\begin{array}{l}\text { 8- Toschke } \\
\text { AM et al, } \\
\text { 2002; } \\
\text { República } \\
\text { Tcheca. }\end{array}$ & $\begin{array}{l}\text { Retrospectivo } \\
\text { Transversal } \\
1991\end{array}$ & $\begin{array}{l}n=33768 \\
6 \text { a } 14 \\
\text { anos }\end{array}$ & $\begin{array}{l}\text { Peso ao nascer; IMC; } \\
\text { IMC pais; tabagismo } \\
\text { materno; escolaridade } \\
\text { (maior nível pai ou mãe); } \\
\text { horas assistindo TV; } \mathrm{n}^{\circ} \text { de } \\
\text { irmãos; atividade física; } \\
\text { consumo de frutas. } \\
\text { Obesidade> percentil } 97 \\
\text { Sobrepeso > percentil } 90\end{array}$ & $\begin{array}{l}\text { NAM } \\
\text { AM: } 1 \\
\text { mês; > 1 e } \\
\leq 3 \text { meses; > } \\
3 \mathrm{e} \leq 6 \\
\text { meses; }>6 \\
\text { meses } \\
\text { *não houve } \\
\text { distinção } \\
\text { entre AME } \\
\text { e AMP }\end{array}$ & $\begin{array}{l}\text { Regressão logística } \\
\text { múltipla } \\
\checkmark \text { Sobrepeso: OR=0,80 } \\
\text { IC 95\% }(0,71-0,90) \\
\checkmark \text { Obesidade: OR=0,80 } \\
\text { IC 95\% }(0,66-0,96) \\
\checkmark \text { Variáveis de confusão: } \\
\text { peso ao nascer e } \\
\text { obesidade dos pais } \\
\checkmark \text { Variáveis de controle: } \\
\text { escolaridade dos pais; } \\
\text { obesidade pais; } \\
\text { tabagismo materno; peso } \\
\text { ao nascer; atividade } \\
\text { física; tempo assistindo } \\
\text { televisão e } n^{\circ} \text { de irmãos. }\end{array}$ \\
\hline $\begin{array}{l}\text { 9-Bergmann } \\
\text { KE, Von } \\
\text { Kries R } \text { et } \\
\text { al; 2003; } \\
\text { Alemanha. }\end{array}$ & $\begin{array}{r}\text { Prospectivo } \\
\text { Longitudinal }\end{array}$ & $\begin{array}{l}n=1314 \\
0 \text { a } 6 \text { anos }\end{array}$ & $\begin{array}{l}\text { Peso; altura; pregas } \\
\text { cutâneas (tricipital e } \\
\text { subescapular); peso ao } \\
\text { nascer; sexo; idade } \\
\text { gestacional; escolaridade } \\
\text { e idade materna; IMC } \\
\text { pais; classe sócio } \\
\text { econômica; tabagismo. } \\
\text { Sobrepeso : percentil } 90 \\
\text { p/IMC e pregas } \\
\text { Obesidade: percentil } 97 \\
\text { p/IMC e pregas }\end{array}$ & $\begin{array}{l}\text { AM (acima } \\
\text { de } 3 \text { meses) } \\
\text { AA } \\
\text { (receberam } \\
\text { aleitamento } \\
\text { por menos } \\
\text { de } 3 \text { meses } \\
\text { ou nunca } \\
\text { receberam) }\end{array}$ & $\begin{array}{l}\text { Regressão logística } \\
\text { múltipla } \\
\checkmark \text { Sobrepeso: OR }=0,53 \\
\text { IC } 95 \%(0,31-0,89) \\
\checkmark \text { Obesidade: OR }=0,46 \\
\text { IC } 95 \%(0,23-0,92) \\
\checkmark \text { Variáveis de ajuste: } \\
\text { obesidade e tabagismo } \\
\text { materno e classe } \\
\text { socioeconômica. }\end{array}$ \\
\hline $\begin{array}{l}\text { 10- Li l, } \\
\text { Parsons T et } \\
\text { al, 2003, } \\
\text { Inglaterra. }\end{array}$ & $\begin{array}{l}\text { Retrospectivo } \\
\text { Transversal } \\
1991\end{array}$ & $\begin{array}{l}n=2631 \\
4 \text { a } 18 \\
\text { anos }\end{array}$ & $\begin{array}{l}\text { Peso e altura atuais; peso } \\
\text { ao nascer; tabagismo na } \\
\text { gravidez; classe sócio } \\
\text { econômica (medida pela } \\
\text { ocupação do chefe de } \\
\text { família); IMC pais (só um } \\
\text { membro-pai ou mãe fazia } \\
\text { parte da coorte), nº de } \\
\text { irmãos. } \\
\text { Obesidade IMC> } \\
\text { percentil } 95\end{array}$ & $\begin{array}{l}\text { AM } \\
<1 \text { semana; } \\
1 \text { semana a } \\
1 \text { mês; } 2-3 \\
\text { meses; } 4-6 \\
\text { meses; } 7-9 \\
\text { meses; }>9 \\
\text { meses }\end{array}$ & $\begin{array}{l}\text { Regressão linear e } \\
\text { múltipla } \\
\checkmark \text { Não encontrou } \\
\text { associação significativa }\end{array}$ \\
\hline $\begin{array}{l}\text { 11-Parsons } \\
\text { TJ et al, } \\
\text { 2003, } \\
\text { Inglaterra. }\end{array}$ & $\begin{array}{l}\text { Retrospectivo } \\
\text { Longitudinal } \\
\text { (coorte) }\end{array}$ & $\begin{array}{l}7 \text { anos: } \\
n=12857 \\
33 \text { anos: } \\
n=9287\end{array}$ & $\begin{array}{l}\text { Sexo; IMC; classe sócio- } \\
\text { econômica; IMC materno; } \\
\text { tabagismo durante } \\
\text { gravidez; paridade; peso } \\
\text { ao nascer; ordem } \\
\text { nascimento } \\
\text { Obesidade IMC } \geq \\
\text { percentil 95 }\end{array}$ & $\begin{array}{l}\text { AM } \\
\text { AMP } \\
>1 M E \hat{E} S \\
<1 \text { MÊS } \\
\text { NAM }\end{array}$ & $\begin{array}{l}\text { Regressão linear } \\
\checkmark \text { Não encontrou } \\
\text { associação significativa. }\end{array}$ \\
\hline
\end{tabular}




\begin{tabular}{|c|c|c|c|c|c|}
\hline $\begin{array}{c}\text { Autor/ } \\
\text { ano/local }\end{array}$ & $\begin{array}{l}\text { Método/ tipo } \\
\text { de estudo }\end{array}$ & $\mathrm{N} /$ idade & $\begin{array}{c}\text { Variáveis/definição } \\
\text { sobrepeso/ } \\
\text { obesidade }\end{array}$ & $\begin{array}{c}\text { Definicao } \\
\text { AM }\end{array}$ & $\begin{array}{c}\text { Técnica } \\
\text { estatística/resultados }\end{array}$ \\
\hline $\begin{array}{l}\text { 12- Victora } \\
\text { CG et al, } \\
\text { 2003, Brasil }\end{array}$ & $\begin{array}{l}\text { Prospectivo } \\
\begin{array}{l}\text { Longitudinal } \\
\text { (coorte) }\end{array} \\
1982-2000\end{array}$ & $\begin{array}{l}n=2250 \\
(18 \text { anos })\end{array}$ & $\begin{array}{l}\text { Renda familiar; } \\
\text { escolaridade materna; } \\
\text { IMC pré-gestacional; } \\
\text { tabagismo durante a } \\
\text { gravidez; peso ao nascer; } \\
\text { idade gestacional; cor da } \\
\text { pele; atividade física; tipo } \\
\text { de dieta (classificação de } \\
\text { Block p/ dietas rica } \\
\text { gordura); tabagismo, } \\
\text { consumo de álcool, IMC, } \\
\text { prega subescapular e } \\
\text { tricipital, biompedância. } \\
\text { Sobrepeso IMC } \geq \\
\text { percentil } 85 \\
\text { Obesidade IMC } \geq \\
\text { percentil } 85 \text { + pregas } \\
\text { tricipital e subescapular } \\
\text { Z percentil 90 }\end{array}$ & $\begin{array}{l}\text { AM } \\
\text { AMP } \\
<1 ; 1-2 ; 3- \\
5 ; 6-8 ; 9-11 ; \\
>12 \\
\text { a } \\
\text { prevalência } \\
\text { do AME foi } \\
\text { muito baixa, } \\
\text { não } \\
\text { entrando nas } \\
\text { análises } \\
\text { estatísticas }\end{array}$ & $\begin{array}{l}\checkmark \text { Regressão logística } \\
\text { múltipla } \\
\checkmark \text { O autor conclui que, de } \\
\text { todo, os resultados não } \\
\text { são consistentes, mas } \\
\text { que, após ajuste, } \\
\text { encontrou } 2 \text { associações } \\
\text { significativas: } 50 \% \text { de } \\
\text { redução da obesidade p/ } \\
\text { os que receberam AM } \\
\text { por 3-5 meses e tendência } \\
\text { linear p/ redução da } \\
\text { obesidade de acordo c/ a } \\
\text { duração do AMP. }\end{array}$ \\
\hline
\end{tabular}

\subsection{Possíveis mecanismos subjacentes à associação entre aleitamento materno e risco para obesidade e sobrepeso na infância e adolescência}

Muitas hipóteses vêm sendo levantadas para explicar o motivo pelo qual o aleitamento materno pode proteger a criança contra a obesidade. Os mecanismos protetores envolveriam desde a composição específica e única do leite humano até a influência de fatores ambientais e comportamentais como nível sócioeconômico, escolaridade materna, padrão alimentar e atividade física. Esses mecanismos, no entanto, ainda não estão bem definidos.

Estudos demonstram diferenças quanto ao teor de proteínas e lipídeos contidos no leite materno em relação à composição dos leites industrializados (Agostini, 2000; Butte, 2001, Dewey, 1993 ; Uauy, 2000). Dewey e col.(1993) observaram que a ingestão 
de proteínas em crianças que recebiam aleitamento artificial era, aproximadamente, $70 \%$ maior do que em crianças que recebiam aleitamento materno. Do mesmo modo, o volume ingerido e a densidade calórica também eram maiores. Rolland Cachera e col. (1995) propõem que a alta ingestão protéica no início da infância predispõe à obesidade na vida adulta. Em estudo com animais, Desai et al (1997) observaram que a disponibilidade de proteína no desenvolvimento fetal e pós-natal favorece efeitos metabólicos prolongados no metabolismo da glicose e na composição corporal na vida adulta. Quanto aos lipídeos, o fato de o leite materno conter maior teor desse nutriente, poderia estar relacionado ao desenvolvimento mais eficiente de mecanismos de controle do apetite. Desta forma, crianças que recebem aleitamento materno estariam protegidas contra obesidade por possuir maior controle da ingestão alimentar (Hall B, 1975; Nommsen, 1991). Esses mecanismos poderiam atuar como "modeladores do metabolismo" de forma a exercer influência ao longo da vida.

Ainda em relação ao desenvolvimento do autocontrole sobre a ingestão, as crianças que recebem aleitamento materno têm a vantagem de controlar sua ingestão de acordo com suas necessidades e de perceber melhor os sinais de saciedade; enquanto aquelas que recebem mamadeira são estimuladas a consumir todo o volume, mesmo já estando saciadas (Dewey, 1986). Esse mecanismo estaria relacionado ao desenvolvimento da habilidade de controle da ingesta calórica que também poderia ter reflexos futuros - apesar de essa hipótese ainda não ter sido confirmada.

Outra hipótese estaria relacionada à insulina, que tem um papel importante na adiposidade. A insulina é responsável pelo aumento da captação celular de glicose e 
inibição da lipólise, o que provoca o aumento da deposição de gordura. Lucas et al (1980) relataram que o nível plasmático de insulina é mais elevado nas crianças que recebem aleitamento artificial e desta forma essas crianças se tornam mais susceptíveis à obesidade. Um dos mecanismos que poderia influenciar o nível de insulina em crianças que recebem aleitamento artificial seria a quantidade de proteína ingerida; em outras palavras, quanto maior a ingestão protéica, maior a secreção de insulina (Dewey, 1993; Rolland Cachera, 1995; Scaglioni, 2000).

Também está documentado que o excesso de ingestão calórica durante a infância leva ao aumento de células adiposas - o que aumenta o risco para obesidade. Em outro extremo, a privação calórica ou uma precária ingestão calórica também eleva os riscos para a obesidade. Assim, uma nutrição adequada, através do aleitamento materno, poderia ser um fator protetor contra a obesidade (Martorell et al, 2001).

O fato de crianças amamentadas terem um menor ganho de peso nos primeiros meses de vida - quando comparadas às que recebem aleitamento artificial - também poderia expressar o efeito protetor do aleitamento materno. Stettler et al (2002) concluíram que um maior ganho de peso nos primeiros quatro meses de vida estava associado ao aumento do risco para sobrepeso em crianças americanas. Esta associação seria independente do peso ao nascer ou do peso com um ano de idade.

Há ainda que se destacar que a leptina, encontrada no leite humano, atua como reguladora da ingestão e do metabolismo energético, havendo hipóteses de que esse hormônio possa contribuir para as diferenças na composição corporal de crianças que 
receberam aleitamento materno e artificial, influenciando o desenvolvimento da obesidade na vida adulta (Hanl, 2000; Singhal, 2002). 


\section{OBJETIVO}

Examinar a associação entre freqüência e duração do aleitamento materno na infância e a obesidade na idade escolar (6 a 14 anos) em famílias de alto nível socioeconômico da cidade de São Paulo. 


\section{METODOLOGIA}

\subsection{Tipo de estudo}

Estudo transversal.

\subsection{População estudada}

A associação entre a freqüência e duração do aleitamento materno e a ocorrência de obesidade na idade escolar foi estudada no conjunto das crianças e adolescentes com idades entre 6 e 14 anos matriculados nas classes do ensino fundamental de uma escola particular situada em um bairro de classe média (Perdizes) do município de São Paulo. Devido ao elevado custo de sua mensalidade (cerca de $\mathrm{R} \$ 800,00$ ), a referida escola atende a famílias de alto nível socioeconômico.

\subsection{Cálculo da amostra}

A amostra calculada para o estudo foi de, no mínimo, 522 indivíduos. Assumindo-se uma prevalência de crianças expostas (não amamentadas por pelo menos 3 meses) de 50\%, a referida amostra permitiria, com nível de significância de $5 \%$ e poder do teste de $90 \%$, identificar como significativas razões de odds para a prevalência de obesidade de pelo menos 1,5 (OMS, 1991).

Em fevereiro de 2004, quando do início do estudo, o total de crianças matriculadas nas classes do ensino fundamental era de 742 . Houve uma perda de aproximadamente $25 \%$ da amostra inicial: cerca de $20 \%(\mathrm{n}=147)$ não devolveram o questionário preenchido; 4\% não preencheram algumas das informações necessárias 
para o estudo $(n=34)$ e $1 \%$ dos escolares $(n=6)$ não foi autorizado pelos pais a participar da pesquisa. Portanto a amostra final deste estudo foi composta de 555 escolares.

\subsection{Coleta de dados}

A primeira fase do estudo consistiu na tomada de medida de peso, altura e dobras cutâneas (tricipital e subescapular) dos integrantes da amostra. A avaliação antropométrica foi realizada no início do ano letivo de 2004, durante as aulas de Educação Física. As medidas de peso e altura foram tomadas pela autora e pelos professores de Educação Física da escola, os quais haviam recebido treinamento prévio. Os alunos foram pesados e medidos com roupas leves e descalços, tendo sido utilizados balança eletrônica com bateria solar com precisão de $200 \mathrm{~g}$ e estadiômetro com precisão de $0,1 \mathrm{~cm}$. Utilizando calibrador com precisão de $0,1 \mathrm{~mm}$, as medidas das pregas cutâneas foram tomadas duas vezes pela autora, empregando-se a média das duas medidas quando houve diferenças entre as mesmas.

A segunda etapa do estudo consistiu no preenchimento, pelas mães dos alunos, de um questionário estruturado com 66 questões (anexo 3). O questionário foi encaminhado às mães por meio dos alunos. Todas as mães receberam uma carta da escola esclarecendo sobre a pesquisa.

\subsection{Análise dos dados}

\subsubsection{Variáveis do estudo}

A variável desfecho do estudo foi a obesidade em crianças e adolescentes. 
Para o diagnóstico de obesidade, foi adotado o critério proposto pela OMS (1995). Segundo esse critério, são classificados como obesos adolescentes e crianças com Índice de Massa Corporal (IMC) e pregas cutâneas triciptal e subescapular acima de valores críticos da distribuição de referência segundo idade e sexo. No caso do IMC, o valor crítico corresponde ao percentil 85 e, no caso das pregas cutâneas, ao percentil 90. A distribuição de referência adotada pela OMS é a da National Center for Health Statistics (NCHS).

As variáveis explanatórias do estudo referem-se à ocorrência e ao período de amamentação da criança, estudando-se o período em que a criança recebeu leite materno, acompanhado ou não por outros alimentos (AM) no $1^{\circ}$ ano de vida.

As potenciais variáveis de confusão do estudo foram divididas em dois grupos:

(a) Referentes às crianças e adolescentes: sexo; idade; peso ao nascer; padrão alimentar; padrão de atividade física (prática de esporte ou exercício físico, tempo vendo televisão ou utilizando o computador).

(b) Referentes às mães: idade; Índice de Massa Corporal (peso em kg dividido pela altura $\mathrm{em}^{2}$ ) calculado a partir de medidas referidas pelas mães; escolaridade; e padrão de atividade física (prática de esporte ou exercício físico).

Quanto à variável padrão alimentar, vale ressaltar que uma das hipóteses para o mecanismo de proteção do aleitamento materno contra a obesidade supõe que a prática 
do aleitamento materno na infância poderia influenciar as preferências alimentares da criança, ou seja, crianças que não recebessem aleitamento materno poderiam desenvolver preferências alimentares que se associam à obesidade. Assim sendo, poderia não ser correto controlar o padrão alimentar da criança quando o objetivo fosse avaliar a influencia da prática da amamentação na infância sobre o risco de obesidade na idade escolar. Outra razão que não recomendaria o controle do padrão alimentar atual da criança seria o fato de que em estudos transversais não se pode eliminar a hipótese de causalidade reversa, ou seja, o padrão alimentar aferido pelo estudo poderia ser conseqüência e não causa do sobrepeso ou obesidade.

De qualquer forma, por ser o padrão alimentar uma variável importante, optou-se por não descartar, de início, o controle da mesma no estudo da associação entre freqüência e duração do aleitamento materno e obesidade.

Para avaliar o padrão alimentar da criança, foi elaborado um escore de alimentação saudável baseado em um questionário de frequêencia alimentar (anexo 3). Os alimentos utilizados na elaboração do escore foram classificados em 2 grupos: alimentos "saudáveis" (feijão, salada crua, frutas, legumes e verduras cozidos, leite) e alimentos "não saudáveis" (batata frita, hambúrguer, biscoitos salgadinhos, biscoitos doces recheados, refrigerantes).

Ressalta-se que, apesar do questionário de frequêencia alimentar incluir 12 tipos de alimentos, 2 foram excluídos porque o grupo de alimentos "saudáveis" incluía 5 tipos de alimentos, enquanto o grupo de alimentos "não saudáveis" incluía 7 tipos de 
alimentos. Para que fosse elaborado o escore de alimentação saudável, os 2 tipos de alimentos menos representativos na população estudada (cachorro quente e salgados) foram excluídos. Também foram excluídos os casos de missing values.

Os alimentos "saudáveis" foram pontuados positivamente sendo o número de pontos equivalente à freqüência semanal de consumo do alimento (número de dias por semana, variando de zero a sete). Os alimentos "não saudáveis" foram pontuados negativamente de modo equivalente ao efetuado para os alimentos "saudáveis". O escore de alimentação saudável de cada criança foi calculado a partir da soma algébrica dos pontos atribuídos aos grupos de alimentos "saudáveis" e "não saudáveis", podendo variar de -35 (consumo diário de todos os alimentos "não saudáveis" e nenhum consumo de alimentos "saudáveis") a +35 (consumo diário de todos os alimentos "saudáveis" e nenhum consumo de alimentos "não saudáveis").

A partir da distribuição do escore de alimentação "saudável" na população estudada foram definidos tercis do escore de alimentação saudável, de modo que a pontuação de -35 a +7 correspondeu ao $1^{\circ}$ tercil (padrão menos saudável de alimentação), pontuação entre $+8 \mathrm{e}+15$ correspondeu ao $2^{\circ}$ tercil (padrão intermediário de alimentação) e pontuação entre +16 e +35 correspondeu ao $3^{\circ}$ tercil (padrão mais saudável de alimentação).

O quadro 2 relaciona as variáveis consideradas pelo presente estudo e a categorização adotada para as mesmas. 
Quadro 2 - Variáveis incluídas no estudo

\begin{tabular}{|c|c|c|}
\hline Tipo & Variável & Categorias \\
\hline Desfecho & Obesidade & Sim/não \\
\hline Exposição & $\begin{array}{l}\text { Ocorrência e duração do aleitamento } \\
\text { materno (em meses) }\end{array}$ & $\begin{array}{l}\text { Nunca recebeu aleitamento materno } \\
\text { Menos de } 3 \\
\text { De } 3 \text { a } 5 \\
\text { De } 6 \text { a } 11 \\
12 \text { ou mais }\end{array}$ \\
\hline Controle & Sexo & Masculino/ Feminino \\
\hline \multirow[t]{6}{*}{$\begin{array}{l}\text { Referentes às características } \\
\text { das crianças e adolescentes }\end{array}$} & Idade (em anos) & $\begin{array}{l}6 \text { a } 8 \\
9 \text { a } 11 \\
12 \text { a } 14 \\
\end{array}$ \\
\hline & Peso ao nascer (em kg) & $\begin{array}{l}<2.5 \\
2.5-2.99 \\
3.0-3.49 \\
3.5-3.99 \\
>4.0\end{array}$ \\
\hline & Padrão alimentar & $\begin{array}{l}1^{\circ} \text { tercil } \\
2^{\circ} \text { tercil } \\
3^{\circ} \text { tercil }\end{array}$ \\
\hline & $\begin{array}{l}\text { Freqüência semanal de esporte ou } \\
\text { exercício físico (mínimo de } 60 \text { minutos) }\end{array}$ & $\begin{array}{l}\text { Não pratica } \\
1 \text { a } 2 \text { dias } \\
3 \text { a } 4 \text { dias } \\
>=5 \text { dias }\end{array}$ \\
\hline & Hábito de ver televisão & $\begin{array}{l}\text { Não vê ou vê apenas raramente } \\
\text { Até } 2 \text { horas por dia } \\
\text { De } 3 \text { a } 4 \text { horas por dia } \\
>=5 \text { horas por dia }\end{array}$ \\
\hline & $\begin{array}{l}\text { Hábito de jogar vídeo games ou outros } \\
\text { jogos no computador }\end{array}$ & $\begin{array}{l}\text { Não joga ou joga apenas raramente } \\
\text { Até } 1 \text { hora por dia } \\
2 \text { horas ou mais por dia }\end{array}$ \\
\hline \multirow[t]{5}{*}{$\begin{array}{l}\text { Controle } \\
\text { Referentes às características } \\
\text { das mães das crianças e } \\
\text { adolescentes }\end{array}$} & Idade (em anos) & $\begin{array}{l}25 \text { a } 30 \\
30 \text { a } 34,9 \\
35 \text { a } 39,9 \\
40 \text { a } 44,9 \\
45 \text { a } 49,9 \\
>=50\end{array}$ \\
\hline & IMC $\left(\mathbf{k g} / \mathbf{m}^{2}\right)$ & $\begin{array}{l}<25 \\
25-29,9 \\
>=30\end{array}$ \\
\hline & Escolaridade & $\begin{array}{l}\text { Até } 2^{\circ} \text { grau } \\
\text { Superior } \\
\text { Pós graduação } \\
\end{array}$ \\
\hline & Tabagismo atual & Sim/ Não \\
\hline & $\begin{array}{l}\text { Freqüência semanal de esporte ou } \\
\text { exercício físico (mínimo de } 30 \text { minutos) }\end{array}$ & $\begin{array}{l}\text { Não pratica } \\
1 \text { a } 2 \text { dias } \\
3 \text { ou } 4 \text { dias } \\
>=5 \text { dias }\end{array}$ \\
\hline
\end{tabular}




\subsubsection{Procedimentos analíticos}

Na primeira etapa da análise dos dados, foi realizada uma análise da consistência do banco de dados, o que possibilitou correções e o preparo do banco de dados definitivo. Com a finalidade de melhor conhecer e entender todas as variáveis, foi realizada uma análise descritiva com base nas distribuições de freqüências simples de todas as variáveis. Os pontos de corte utilizados para categorização das variáveis foram baseados na distribuição de cada variável e também de acordo com a literatura.

Inicialmente, foram realizadas análises bivariadas da associação entre regime de aleitamento no primeiro ano de vida e obesidade na idade escolar, utilizando-se na análise estatística o cálculo do qui-quadrado $\left(\chi^{2}\right)$ de Pearson. $O \chi^{2}$ de tendência linear foi empregado quando havia mais de duas categorias de regime de aleitamento e suposição de tendência linear na relação entre aleitamento e obesidade. Nas análises, adotou-se o nível de significância de 5\%.

A seguir, para seleção das potenciais variáveis de confusão para a associação entre regime de aleitamento e obesidade, foram realizadas análises bivariadas entre potenciais variáveis de confusão e obesidade (teste do $\chi^{2}$ simples ou de tendência), utilizando-se como ponto de corte para seleção $\mathrm{p}<0,2$.

Finalmente, foram realizadas análises de regressão logística múltipla para estudar a relação entre regime de aleitamento nos primeiros anos de vida e obesidade na idade escolar, com controle de variáveis de confusão. O processo de modelagem foi realizado através do método stepwise forward selection, ou seja, partiu-se de um modelo mais 
simples para um mais complexo, acrescentando as variáveis de confusão de acordo com valores crescentes de $\mathrm{p}$ obtidos na análise bivariada. O controle das variáveis de confusão foi realizado, adicionando-se ao modelo de regressão logística as potenciais variáveis de confusão estudadas, uma a uma, mantendo no modelo final todas aquelas que modificaram em pelo menos $10 \%$ a magnitude do odds ratio entre aleitamento materno e excesso de peso.

O programa utilizado na análise estatística foi o STATA 6.0.

\section{6. Ética em pesquisa}

Esta pesquisa está de acordo com as normas da Resolução nº 196, de 10/10/1996 do Conselho Nacional de Saúde e foi aprovada pelo Comitê de Ética e Pesquisa da USP (anexo 1).

Antes de ser iniciada a coleta de dados, foi realizada uma reunião com as coordenadoras de curso, os professores de Educação Física e a nutricionista da escola a fim de serem esclarecidas as etapas e os objetivos da pesquisa.

Apesar de a escola ter como rotina, a cada início e final de ano letivo, a tomada de medidas de peso e altura, antes da avaliação nutricional - medidas de peso, altura e dobras cutâneas - cada turma foi esclarecida quanto à realização da pesquisa. Ressalte-se que nenhum aluno se recusou a participar da mesma. 
O Termo de Consentimento Livre e Esclarecido (anexo 2), o questionário estruturado (anexo 3) e uma carta da escola (anexo 4) foram encaminhados às mães através dos próprios alunos.

Pelo fato de a avaliação nutricional fazer parte da rotina da escola, - exceto tomada de medidas de pregas cutâneas - e de ter sido realizada antes da aplicação dos questionários, constava do Termo de Consentimento Livre e Esclarecido que, em caso de não autorização pelos responsáveis, os dados dos alunos não autorizados não seriam utilizados no estudo.

O resultado da avaliação física foi apresentado à Coordenadora Geral e à nutricionista da escola por meio de explanação oral, seguida de entrega de um relatório com todos os dados obtidos.

No relatório entregue, além do resultado da avaliação física, foram inseridas sugestões para melhoria da qualidade de vida dos alunos, como, por exemplo, modificações na oferta de alimentos saudáveis pela cantina da escola e atividades curriculares sobre Nutrição e Atividade Física.

Por solicitação da escola, como forma de devolver aos alunos o resultado da avaliação nutricional, foi preparado e encaminhado aos seus responsáveis um folder contendo o resultado da avaliação nutricional de cada aluno e algumas orientações relativas à alimentação saudável. (anexo 5). 


\section{RESULTADOS}

\subsection{Caracterização da população de estudo}

Participaram desta pesquisa 555 crianças e adolescentes estudantes de uma escola particular situada na zona sul da cidade de São Paulo.

Indicadores antropométricos, do regime de aleitamento materno e de obesidade das crianças estudadas estão apresentados na Tabela 1. Verifica-se que a prevalência de obesidade foi de $26 \%$ e que $92,6 \%$ das crianças receberam aleitamento materno em algum momento de suas vidas, sendo que $78,8 \%$ receberam aleitamento materno por pelo menos 3 meses.

Indicadores demográficos e de condições de nascimento das crianças estudadas estão na Tabela 2, onde se observa que a amostra está bem distribuída entre os sexos masculino $(54,4 \%)$ e feminino $(45,6 \%)$ e entre as idades de 6 a 8 anos $(29,0 \%), 9$ a 11 anos $(37,1 \%)$ e de 12 a 14 anos $(33,9 \%)$. A idade média foi de 10,11 anos e o desvio padrão foi de 2,39 anos. Apenas 4,5\% das crianças e adolescentes nasceram com peso menor do que $2,5 \mathrm{~kg}$, enquanto $5,7 \%$ das crianças nasceram com peso maior ou igual a $4 \mathrm{~kg}$. A maioria das crianças pratica esporte ou exercício físico por pelo menos 60 minutos diários em 1 ou 2 dias da semana ( $34 \%$ ) ou em 3 ou 4 dias da semana ( $31 \%$ ). Apenas 3,4\% das crianças não vêem televisão regularmente enquanto grande parte vê todos os dias ou quase todos os dias por até 2 horas diárias $(44,6 \%)$ ou 3 a 4 horas 
diárias $(39,6 \%)$. Em relação a jogos no computador ou video games, quase metade das crianças $(41,3 \%)$ tem o hábito diário desta prática.

As características das mães dos escolares estudados estão resumidas na Tabela 3. O nível de escolaridade das mães é bastante elevado: $63 \%$ possuem ensino superior e cerca de $18 \%$ são pós-graduadas. Quanto ao tabagismo, 11,3\% têm no momento o hábito de fumar. Dentre as mães que relataram peso e altura $(91,5 \%), 23,2 \%$ apresentaram sobrepeso e $5,9 \%$ obesidade, sendo o IMC médio de $23,6 \mathrm{~kg} / \mathrm{m}^{2}$ com desvio padrão de $3,42 \mathrm{~kg} / \mathrm{m}^{2}$. A idade média das mães foi de 40 anos com desvio padrão de 5,5 anos. Em relação à frequiência semanal de exercícios físicos (mínimo de 30 minutos), apenas 13,2\% das mães declararam fazê-los em 5 ou mais dias da semana, enquanto cerca de metade das mães não fazia exercícios físicos. 
Tabela 1 - Distribuição da amostra, segundo indicadores de aleitamento materno e obesidade. Estudantes do ensino fundamental de uma escola particular de alto nível socioeconômico do município de São Paulo (2004).

\begin{tabular}{ccc}
\hline Variável & n & \% \\
\hline Recebeu aleitamento materno & 514 & 92,6 \\
Sim & 41 & 7,4 \\
Não & & 7,6 \\
Duração do aleitamento (meses)* & 41 & 13,6 \\
0 & 74 & 24,3 \\
$<3$ & 132 & 38,7 \\
$3-5$ & 210 & 15,8 \\
$6-11$ & 86 & 26,0 \\
$>=12$ & & 74,0 \\
Sim & 144 & \\
Não & 411 & 61,3 \\
Obesidade & & 38,7 \\
IMC >=percentil 85 & 340 & 64,9 \\
Sim & 215 & 35,1 \\
Não & & \\
Prega Tricipital >=percentil 90 & 369 & \\
Sim & 195 & 66,9 \\
Não & & 33,1 \\
Prega Subescapular >=percentil 90 & & \\
Sim & 371 & 184 \\
Não & & \\
\hline
\end{tabular}

* A soma das crianças estudadas é inferior a 555 devido à ausência de resposta para a variável em questão. 
Tabela 2 - Distribuição da amostra, segundo características demográficas, peso ao nascer e padrão de atividade física e alimentar. Estudantes do ensino fundamental de uma escola particular de alto nível socioeconômico do município de São Paulo (2004).

\begin{tabular}{|c|c|c|}
\hline Variável & n & $\%$ \\
\hline \multicolumn{3}{|l|}{ Sexo } \\
\hline Masculino & 302 & 54,4 \\
\hline Feminino & 253 & 45,6 \\
\hline \multicolumn{3}{|l|}{ Faixa etária (em anos) } \\
\hline 6 a 8 & 161 & 29,0 \\
\hline 9 a 11 & 206 & 37,1 \\
\hline 12 a 14 & 188 & 33,9 \\
\hline \multicolumn{3}{|l|}{ Peso ao nascer* (em kg) } \\
\hline$<2.5$ & 24 & 4,5 \\
\hline $2.5-2.99$ & 93 & 17,5 \\
\hline $3.0-3.49$ & 240 & 45,2 \\
\hline $3.5-3.99$ & 144 & 27,1 \\
\hline$>4.0 \mathrm{~kg}$ & 30 & 5,7 \\
\hline \multicolumn{3}{|c|}{ Frequiência semanal de atividade física* (mínimo de 60 minutos) } \\
\hline Não pratica & 115 & 21,5 \\
\hline 1 a 2 dias & 182 & 34,0 \\
\hline 3 a 4 dias & 166 & 31,0 \\
\hline$>=5$ dias & 72 & 13,5 \\
\hline \multicolumn{3}{|l|}{ Hábito de ver televisão* } \\
\hline Não vê ou vê apenas raramente & 19 & 3,4 \\
\hline Até 2 horas por dia & 245 & 44,6 \\
\hline De 3 a 4 horas por dia & 218 & 39,6 \\
\hline$>=5 \mathrm{~h}$ por dia & 68 & 12,4 \\
\hline \multicolumn{3}{|l|}{ Hábito de jogar no computador* } \\
\hline Não joga ou joga raramente & 325 & 58,7 \\
\hline Até 1 hora por dia & 128 & 23,1 \\
\hline 2 ou mais horas por dia & 101 & 18,2 \\
\hline \multicolumn{3}{|l|}{ Escore de alimentação saudável* } \\
\hline $1^{\circ}$ tercil & 185 & 34,3 \\
\hline $2^{\circ}$ tercil & 185 & 34,3 \\
\hline $3^{\circ}$ tercil & 170 & 31,4 \\
\hline
\end{tabular}

* A soma das crianças estudadas é inferior a 555 devido à ausência de resposta para a variável em questão. 
Tabela 3 - Distribuição da amostra, segundo características maternas. Estudantes do ensino fundamental de uma escola particular de alto nível socioeconômico do município de São Paulo (2004).

\begin{tabular}{|c|c|c|}
\hline Características maternas & $\bar{n}$ & $\%$ \\
\hline \multicolumn{3}{|l|}{ Hábito de fumo atual * } \\
\hline Sim & 62 & 11,3 \\
\hline Não & 487 & 88,7 \\
\hline \multicolumn{3}{|l|}{ Escolaridade* } \\
\hline Até o $2^{\circ}$ grau & 110 & 20,2 \\
\hline Superior & 336 & 62,7 \\
\hline Pós graduação & 99 & 18,2 \\
\hline \multicolumn{3}{|l|}{$\operatorname{IMC}\left(\mathbf{k g} / \mathbf{m}^{2}\right)^{*}$} \\
\hline$<25$ & 360 & 70,9 \\
\hline $25-29,9$ & 118 & 23,2 \\
\hline$>=30$ & 30 & 5,9 \\
\hline \multicolumn{3}{|l|}{ Idade (em anos)* } \\
\hline $25-30$ & 19 & 3,5 \\
\hline$>30-35$ & 78 & 14,2 \\
\hline$>35-40$ & 211 & 38,4 \\
\hline$>40-45$ & 157 & 28,6 \\
\hline$>45-50$ & 66 & 12,0 \\
\hline$>50$ & 19 & 3,5 \\
\hline \multicolumn{3}{|c|}{$\begin{array}{l}\text { Freqüência semanal de atividade física semanal (mínimo de } 30 \\
\text { minutos) * }\end{array}$} \\
\hline Não pratica & 265 & 49,2 \\
\hline 1 a 2 dias & 85 & 15,8 \\
\hline 3 a 4 dias & 118 & 21,9 \\
\hline$>=5$ dias & 71 & 13,2 \\
\hline
\end{tabular}

* A soma das crianças estudadas é inferior a 555 devido à ausência de resposta para a variável em questão. 


\subsection{Associação entre aleitamento materno e obesidade: análise bivariada}

A associação encontrada entre obesidade e indicadores da freqüência e duração do aleitamento materno está apresentada na Tabela 4. Observa-se que a maior prevalência de obesidade ocorre entre as crianças que nunca receberam aleitamento materno na infância $(36,6 \%)$, seja quando comparadas àquelas que receberam por qualquer duração $(25,1 \%)$, seja quando comparadas às crianças que foram amamentadas por diferentes períodos $(22,1 \%$ a $25,8 \%)$. Entretanto, em nenhuma das comparações o excesso de obesidade nas crianças não amamentadas alcançou significância estatística. De forma a testar a associação entre a prática de aleitamento materno e a obesidade em crianças e adolescentes com um menor número de graus de liberdade, optou-se por reagrupar a variável "duração do aleitamento materno" em 3 categorias: nunca receberam; receberam por menos de um ano e receberam por um ano ou mais. Ainda assim, observou-se que a grande diferença no risco de obesidade permanecia entre as crianças que nunca receberam aleitamento materno na infância e aqueles que receberam e, novamente, não se alcançou significado estatístico na associação entre aleitamento materno na infância e obesidade ( $\mathrm{p}$ de tendência linear $=0,12$ ).

A Tabela 5 apresenta as associações encontradas entre características dos escolares consideradas potenciais variáveis de confusão para a associação de interesse e a prevalência de obesidade. Dentre as variáveis analisadas as que apresentaram valores de p menores ou iguais a 0,20 foram: sexo, faixa etária, peso ao nascer, frequiência semanal de exercício físico, hábito de ver televisão e escore de alimentação saudável. 
O risco de obesidade nos escolares tendeu a diminuir com a idade, foi menor entre meninas do que em meninos $(\mathrm{p}<0,01)$ e tendeu a aumentar com o peso ao nascer $(\mathrm{p}=0,18)$.

Houve tendência a diminuir o risco de obesidade com a pratica de exercício físico $(p=0,10)$ e a aumentar com o número de horas vendo televisão $(p=0,13)$, não se observando um padrão consistente de associação entre o escore de alimentação saudável e a freqüência da obesidade.

A Tabela 6 apresenta a associação encontrada entre características das mães consideradas potenciais variáveis de confusão para a associação de interesse e a prevalência de obesidade nos escolares. As seguintes variáveis maternas mostraram tendência de associação $(p<0,20)$ com a obesidade na amostra: idade e IMC. Observa-se tendência de aumento do risco de obesidade nos escolares com a redução da idade materna $(p=0,07)$ e com o aumento do IMC materno $(p<0,01)$. 
Tabela 4 - Prevalência (\%) de obesidade e Odds Ratio (IC 95\%) segundo indicadores de aleitamento materno. Estudantes do ensino fundamental de uma escola particular de alto nível socioeconômico do município de São Paulo (2004).

\begin{tabular}{ccccc}
\hline Variável & $\%$ & OR & IC 95\% & p \\
\hline Recebeu aleitamento materno & & & & 0,11 \\
$\quad$ Sim & 25,1 & 1,00 & $0,88-3,35$ & \\
$\quad$ Não & 36,6 & 1,72 & & \\
Duração do aleitamento (meses)* & & & & $0,20^{*}$ । \\
0 & 36,6 & 2,03 & $0,90-4,59$ & \\
$<3$ & 24,3 & 1,13 & $0,54-2,37$ & \\
$3-5$ & 25,8 & 1,22 & $0,64-2,32$ & \\
$6-11$ & 25,2 & 1,19 & $0,66-2,16$ & \\
$>=12$ & 22,1 & 1,00 & & \\
Duração do aleitamento (em anos)* & & & & $0,1 *^{*}$ \\
0 & 36,6 & 2,03 & $0,90-4,59$ & \\
$<1$ & 25,2 & 1,19 & $0,68-2,07$ & \\
$>=1$ & 22,1 & 1,00 & & \\
\hline
\end{tabular}

* A soma das crianças estudadas é inferior a 555 devido à ausência de resposta para a variável em questão. $*_{1}=$ teste de tendência linear 
Tabela 5 - Prevalência (\%) de obesidade e Odds Ratio (IC 95\%) segundo sexo, faixa etária, peso ao nascer e padrão de atividade física e alimentar. Estudantes do ensino fundamental de uma escola particular de alto nível socioeconômico do município de São Paulo (2004).

\begin{tabular}{|c|c|c|c|c|}
\hline Variável & $\%$ & OR & IC $95 \%$ & p \\
\hline Sexo & & & & $<0,01$ \\
\hline Masculino & 31,1 & 1,00 & & \\
\hline Feminino & 19,8 & 0,47 & $0,35-0,70$ & \\
\hline Faixa etária $(\mathrm{em} \text { anos })^{*}$ & & & & 0,04 \\
\hline 6 a 8 & 32,3 & 1,88 & $1,16-3,06$ & \\
\hline 9 a 11 & 26,2 & 1,40 & $0,87-2,25$ & \\
\hline 12 a 14 & 20,2 & 1,00 & & \\
\hline
\end{tabular}

Peso ao nascer (em kg)*

$$
\begin{aligned}
& <2.5 \\
& 2.5-2.99 \\
& 3.0-3.49 \\
& 3.5-3.99 \\
& >4.0 \mathrm{~kg}
\end{aligned}
$$

$\begin{array}{lll}29,2 & 1,00 & \\ 17,2 & 0,50 & 0,18-1,42 \\ 25,8 & 0,85 & 0,34-2,14 \\ 27,1 & 0,90 & 0,35-2,34 \\ 26,7 & 0,88 & 0,27-2,92\end{array}$

Peso ao nascer $(\mathrm{em} \mathrm{kg}) *$

$$
\begin{aligned}
& <3.0 \\
& 3.0-3.49 \\
& >=3.5
\end{aligned}
$$

Freqüência semanal de atividade física * (mínimo de 60 minutos)

$$
\begin{aligned}
& \text { Não pratica } \\
& 1 \text { a } 2 \text { dias) } \\
& 3 \text { a } 4 \text { dias } \\
& >=5 \text { dias }
\end{aligned}
$$

\begin{tabular}{llll}
29,6 & 2,10 & $1,00-4,39$ & \\
25,8 & 1,74 & $0,86-3,52$ & \\
26,5 & 1,80 & $0,89-3,66$ & \\
16,7 & 1,00 & & $0,13^{*}$ \\
& & & \\
17,7 & 1,00 & & \\
24,5 & 1,51 & $0,42-5,44$ & \\
26,2 & 1,65 & $0,46-5,96$ & \\
32,9 & 2,29 & $0,60-8,72$ & \\
& & & \\
25,2 & 1,00 & & \\
25,8 & 1,03 & $0,64-1,65$ & \\
27,7 & 1,14 & $0,69-1,88$ & \\
& & & 0,09 \\
31,4 & 1,39 & $0,87-2,22$ & \\
21,6 & 0,84 & $0,51-1,31$ & \\
24,7 & 1,00 & & \\
\hline
\end{tabular}

* A soma das crianças estudadas é inferior a 555 devido à ausência de resposta para a variável em questão.

*1 teste de tendência linear 
Tabela 6 - Prevalência (\%) de obesidade e Odds Ratio (IC 95\%) segundo características maternas. Estudantes do ensino fundamental de uma escola particular de alto nível socioeconômico do município de São Paulo (2004).

\begin{tabular}{|c|c|c|c|c|}
\hline Características maternas & $\%$ & OR & IC $95 \%$ & $\mathbf{P} \mathbf{x}^{2}$ \\
\hline Hábito de fumo atual * & & & & 0,98 \\
\hline Sim & 25,8 & 0,98 & $0,55-1,84$ & \\
\hline Não & 25,7 & 1,00 & & \\
\hline Escolaridade* & & & & 0,63 \\
\hline Até $2^{\circ} \mathrm{grau}$ & 28,2 & 1,05 & $0,57-1,92$ & \\
\hline Superior & 24,1 & 0,85 & $0,51-1,41$ & \\
\hline Pós graduação & 27,3 & 1,00 & & \\
\hline \multicolumn{5}{|l|}{$\operatorname{IMC}\left(\mathbf{k g} / \mathbf{m}^{2}\right)^{*}$} \\
\hline$<25$ & 18,9 & 1,00 & & $<0,01$ \\
\hline $25-29,9$ & 34,8 & 2,29 & $1,44-3,63$ & \\
\hline$>=30$ & 36,7 & 2,49 & $1,13-5,47$ & \\
\hline Idade $(\operatorname{anos}) *$ & & & & $0,07 * 1$ \\
\hline $25-30$ & 42,1 & 1,00 & & \\
\hline$>30-35$ & 26,9 & 0,51 & $0,18-1,43$ & \\
\hline$>35-40$ & 27,5 & 0,52 & $0,20-1,36$ & \\
\hline$>40-45$ & 22,9 & 0,41 & $0,15-1,09$ & \\
\hline$>45-50$ & 22,7 & 0,40 & $0,14-1,19$ & \\
\hline$>50$ & 15,8 & 0,26 & $0,56-1,19$ & \\
\hline \multicolumn{5}{|c|}{ Pratica de atividade física (mínimo de 30 minutos) * } \\
\hline Não pratica & 27,9 & 1,33 & $0,72-2,47$ & 0,35 \\
\hline 1 a 2 dias & 18,8 & 0,80 & $0,37-1,74$ & \\
\hline 3 ou 4 dias & 27,1 & 1,28 & $0,64-2,55$ & \\
\hline$>=5$ dias & 22,5 & 1,00 & & \\
\hline
\end{tabular}

* A soma das crianças estudadas é inferior a 555 devido à ausência de resposta para a

variável em questão.

$*_{1}$ teste de tendência linear

\subsection{Associação entre aleitamento materno e obesidade: análise multivariada}

As potencias variáveis de confusão para a associação entre aleitamento materno e obesidade foram selecionadas a partir da análise bivariada. A inclusão das mesmas nos modelos multivariados seguiu uma ordem crescente, de acordo com valores de $\mathrm{p}$ na análise bivariada. Ressalta-se que todas as variáveis com valores de $\mathrm{p}<0,20$ foram adicionadas ao modelo. A ordem de entrada das variáveis no modelo foi a seguinte: sexo 
da criança, IMC materno, faixa etária da criança, idade materna, padrão alimentar da criança, padrão de atividade física da criança, tempo de televisão da criança e peso ao nascer da criança.

Todas as variáveis que, adicionadas ao modelo, alterassem o odds ratio da $1^{\mathrm{a}}$ categoria (nunca recebeu aleitamento materno) em pelo menos $10 \%$ foram consideradas variáveis de confusão e, portanto, permaneceram no modelo. Esse critério foi definido porque, a princípio, observou-se que a grande diferença quanto à prevalência da obesidade ocorria quando a categoria de crianças nunca amamentadas era comparada com as demais (ver Tabela 4).

Conforme se observa na Tabela 7, as variáveis de confusão, ou seja, aquelas que estavam associadas ao desfecho e que alteraram o odds ratio da $1^{\mathrm{a}}$ categoria do aleitamento materno em $10 \%$ foram: sexo, IMC materno, idade materna e peso ao nascer. Com o controle de todas essas variáveis, continuou-se a observar maior risco de obesidade em crianças nunca amamentadas, mas sem se alcançar significado estatístico e sem se observar efeito dose-resposta na associação entre duração do aleitamento materno e obesidade.

Devido ao fato de a categoria "nunca recebeu aleitamento materno" ter um risco de 2,73 em relação à categoria "recebeu aleitamento por 12 meses ou mais", optou-se por testar um novo modelo re-categorizando a variável "tempo de aleitamento materno" em apenas três categorias: nunca recebeu aleitamento materno; recebeu aleitamento materno por menos de um ano e recebeu aleitamento materno por um ano ou mais, 
observando-se nesse modelo também um risco de 2,73 para a categoria "nunca recebeu aleitamento materno" em relação à categoria "recebeu aleitamento por 12 meses ou mais” mas ainda sem alcançar significado estatístico (Tabela 8).

Também se testou um modelo (Tabela 9) com a variável aleitamento materno dicotômica (recebeu e não recebeu aleitamento materno), sem considerar a duração da prática do aleitamento materno. Neste modelo, observou-se que os escolares que nunca receberam aleitamento materno têm 2 vezes a chance de desenvolver obesidade, sendo, desta vez, o risco estatisticamente significativo. Neste modelo, mostraram-se como variáveis de confusão, ou seja, alteraram o odds ratio da $1^{\text {a }}$ categoria - nunca recebeu aleitamento materno- em pelo menos $10 \%$, a idade materna e o peso ao nascer da criança.

Tabela 7 - Modelo final de regressão logística para a prevalência de obesidade, segundo a duração do aleitamento materno estratificado em 5 categorias. Estudantes do ensino fundamental de uma escola particular de alto nível socioeconômico do município de São Paulo (2004).

\begin{tabular}{|c|c|c|c|c|}
\hline $\begin{array}{l}\text { Duração do aleitamento } \\
\text { materno (em meses) }\end{array}$ & OR bruta & OR ajustada* & $\begin{array}{l}\text { Intervalo de } \\
\text { confiança } 95 \% \\
\end{array}$ & p \\
\hline$\overline{0}$ & 2,03 & 2,73 & $0,98-7,65$ & 0,43 \\
\hline$<3$ & 1,13 & 1,30 & $0,53-3,18$ & \\
\hline $3-5$ & 1,22 & 1,43 & $0,64-3,19$ & \\
\hline $6-11$ & 1,19 & 1,48 & $0,71-3,09$ & \\
\hline$>=12$ & 1,00 & & & \\
\hline
\end{tabular}

*ajustada pelas seguintes variáveis: sexo, IMC materno, idade materna, peso ao nascer.

**teste de tendência linear 
Tabela 8 - Modelo final de regressão logística para a prevalência de obesidade, segundo duração do aleitamento estratificado em 3 categorias. Estudantes do ensino fundamental de uma escola particular de alto nível socioeconômico do município de São Paulo (2004).

\begin{tabular}{lllll}
\hline $\begin{array}{l}\text { Duração do aleitamento } \\
\text { materno (em ano) }\end{array}$ & OR bruta & OR ajustada* & $\begin{array}{l}\text { Intervalo de } \\
\text { confiança 95\% }\end{array}$ & p \\
\hline 0 & 2,03 & 2,73 & $0,98-7,64$ & 0,16 \\
$<1$ & 1,19 & 1,43 & $0,71-2,88$ & \\
$>=1$ & 1,00 & & &
\end{tabular}

*ajustada pelas seguintes variáveis: sexo, IMC materno, idade materna, peso ao nascer.

**teste de tendência linear

Tabela 9 - Modelo final de regressão logística para a prevalência de obesidade, segundo a ocorrência ou não do aleitamento materno. Estudantes do ensino fundamental de uma escola particular de alto nível socioeconômico do município de São Paulo (2004).

\begin{tabular}{lllll}
\hline $\begin{array}{l}\text { Duração do aleitamento } \\
\text { materno (em ano) }\end{array}$ & OR bruta & OR ajustada* & $\begin{array}{l}\text { Intervalo de } \\
\text { confiança 95\% }\end{array}$ & p \\
\hline Sim & 1,00 & & & \\
Não & 1,72 & 2,06 & $1,02-4,16$ & 0,03 \\
\hline
\end{tabular}

*ajustada pela variável idade materna e peso ao nascer. 


\section{DISCUSSÃO}

Verificou-se que, na população de estudantes do ensino fundamental de uma escola particular de alto nível socioeconômico do município de São Paulo, a prevalência de obesidade é maior entre as crianças e adolescentes que nunca receberam aleitamento materno do que entre aquelas que receberam: $36 \%$ e $25 \%$ respectivamente. A prevalência de obesidade na amostra é alarmante e reforça os achados de diversas pesquisas que apontam para o aumento expressivo da obesidade infantil e juvenil nas últimas décadas (Monteiro, 2002; Anjos, 2003; Thorpe, 2004).

O presente estudo sugere um efeito protetor do aleitamento materno contra a obesidade na idade escolar para as crianças que são amamentadas por qualquer período, mas não confirma um efeito dose-resposta da amamentação, efeito encontrado em alguns estudos (Kramer, 1981; Von Kries, 1999; Gilman, 2001; Liese, 2002), mas não em outros (Zive et al, 1992; Elliot, 1997; Hediger, 2001; Toschke, 2002; Bergmann, 2003; Li, 2003; Parsons, 2003 e Victora, 2003).

Quanto à validade interna do nosso estudo, vale destacar três importantes aspectos.

$\mathrm{O}$ primeiro aspecto diz respeito aos possíveis viéses de aferição. $\mathrm{O}$ fato de a avaliação física da amostra ter sido realizada pela pesquisadora responsável por este estudo (pregas cutâneas, peso e altura) e pelos professores de Educação Física (peso e altura) devidamente treinados, diminui a chance de viés de aferição. $A$ aferição da 
variável de exposição "aleitamento materno" foi realizada por meio de questionário estruturado preenchido pelas mães dos estudantes que, conforme se observou na análise dos dados, têm elevado nível de escolaridade. Estudos publicados indicam a acurácia e validade das informações retrospectivas sobre aleitamento materno fornecidas pela mãe (Kark, 1984; Haaga, 1988; Launer, 1992 ).

De grande importância, o segundo aspecto a ser destacado é o controle de potenciais variáveis de confusão citadas na literatura, como peso ao nascer, sexo, faixa etária, estado nutricional e escolaridade da mãe. Em meta-análise realizada sobre a associação entre a prática de aleitamento materno na infância e obesidade na idade escolar, Owen (2005) destaca três importantes variáveis de confusão: obesidade materna, tabagismo materno e classe social. Além do controle de variáveis de consenso na literatura, ainda foram controladas outras possíveis variáveis de confusão para a associação entre aleitamento materno e obesidade na idade escolar, como, por exemplo, exercícios físicos realizados pela mãe e criança e hábito de ver televisão.

Tanto o baixo peso ao nascer $(<2,5 \mathrm{~kg})$ quanto o peso ao nascer maior ou igual a $4 \mathrm{~kg}$ podem ser fatores de risco para obesidade (Ong 2000; Eriksson, 2001; Bergmann, 2003). O peso ao nascer pode ser uma variável de confusão porque crianças que nascem com baixo peso têm mais chances de receber alimentação artificial e, desta forma, supondo que o aleitamento materno seja de fato um fator protetor contra obesidade, o não controle dessa variável poderia determinar uma associação inversa entre aleitamento materno e obesidade (Liese, 2001; Owen, 2005). No presente estudo, o peso ao nascer 
apresentou-se, efetivamente, como uma variável de confusão para a associação entre a obesidade e tempo de duração do aleitamento materno no modelo de regressão logística.

Assim como os achados de Kramer (1981), Zive (1992), Tosckhe (2002) e Bergmann (2003), o presente estudo verificou uma associação significativa $(p<0,01)$ entre sobrepeso ou obesidade materna e a obesidade em crianças. Tal associação pode estar refletindo questões genéticas ou influência ambiental e comportamental. Por outro lado, a obesidade materna está associada a uma menor chance de iniciar a amamentação com sucesso ou a uma maior chance de descontinuar essa prática (Liese, 2001; Bergmann, 2003; Bogen, 2004; Hilson, 2004)

Sabe-se que mães de maior nível socioeconômico e escolaridade têm mais chance de amamentarem os seus filhos e tendem a ter um estilo de vida diferente das outras mães, ou seja, são mais esclarecidas e preocupadas com a saúde, alimentação e prática de atividade física, o que poderia se refletir no estilo de vida de seus filhos (Zive, 1992).

Ward (2004), estudando os fatores que influenciam a iniciação e duração do aleitamento materno, concluiu que as mães com maior escolaridade têm mais chance de iniciarem a amamentação. Do mesmo modo, Bertini (2003), em estudo realizado em Florença, Itália, constatou que a baixa escolaridade materna era um importante fator de risco para a opção de não iniciar a amamentação.

Venâncio (2002), avaliando a frequiência e determinantes do aleitamento materno em municípios do Estado de São Paulo, concluiu que quanto maior a escolaridade 
materna, maior a probabilidade de a criança receber aleitamento materno exclusivo. Também, Kummer et al (2000) observaram tendência de aumento na prevalência do aleitamento materno exclusivo em crianças atendidas em um hospital de Porto Alegre entre 1987 e 1994 sendo significativamente maior entre mulheres com escolaridade maior ou igual a quatro anos, concluindo que mulheres com maior escolaridade estão em fase de valorização do aleitamento materno exclusivo.

O tabagismo materno pode ser proxy de algumas características do comportamento materno como, por exemplo, a atitude da mãe frente à alimentação e ao padrão de atividade física da criança (Bogen, 2004).

O possível efeito de confusão causado pela classe social foi minimizado pelo fato de a amostra ser homogênea, ou seja, os estudantes são todos de alto nível socioeconômico, fato que pode ser evidenciado não só pela localização e valor da mensalidade da escola, como também se utilizando como proxy as escolaridades materna e paterna (Arenz S, 2004; Liberatos P, 1988). Ressalte-se que as variáveis controladas no presente estudo apresentaram resultados consistentes, fato que vem reforçar a qualidade dos dados aferidos.

Por último, ainda em relação à validade interna do estudo, vale destacar o terceiro aspecto, a técnica estatística utilizada nas análises - Regressão Logística Múltipla - que permitiu avaliar o efeito de potenciais variáveis de confusão - aquelas que estão associadas tanto ao desfecho quanto à exposição. 
No que se diz respeito às limitações do nosso estudo, destacam-se o pequeno número de crianças que nunca receberam aleitamento materno $\mathrm{e} o$ delineamento transversal do estudo.

De fato, quando calculamos o tamanho da amostra do estudo, previmos que a proporção de crianças expostas ao risco (não amamentadas por pelo menos de 3 meses) fosse de $50 \%$. Entretanto, a proporção de expostos em nosso estudo correspondeu a apenas $21,2 \%$. Destaca-se ainda o fato de que encontramos um maior risco de obesidade nas crianças que nunca foram amamentadas, o que correspondeu a apenas $7,6 \%$ da amostra. Com isso, para detectar uma razão de odds de 1,5, como planejado, precisaríamos de cerca de 1500 crianças (OMS, 1991). O tamanho amostral pode não ter conferido ao estudo poder de teste suficiente para encontrar um risco estatisticamente significativo

A não observância de um efeito dose-resposta pode ter decorrido do delineamento retrospectivo do nosso estudo. A memória da mãe para lembrar exatamente até quando amamentou pode não ser precisa, o que tende a obscurecer verdadeiras associações entre a duração do aleitamento materno e os diferentes desfechos, levando a razões de odds para a unidade. Ainda assim, ressalta-se mais uma vez, que alguns estudos têm indicado a acurácia e validade das informações retrospectivas sobre aleitamento materno fornecidas pela mãe (Kark, 1984; Haaga, 1988; Launer, 1992). 
Podemos ainda cogitar, como possível justificativa para a ausência de doseresposta, uma possibilidade de efeito de confusão residual que não foi possível controlar no presente estudo.

Outro possível fator que poderia justificar a ausência de dose-resposta seria o fato do nosso estudo não ter avaliado o aleitamento materno exclusivo. Toschke (2002) sugere em sua publicação que a duração do aleitamento materno não necessariamente refletiria um efeito dose-resposta caso a criança não recebesse aleitamento exclusivo. $O$ que se pode observar na literatura é que, exceto o estudo de Kramer (1981), os estudos que encontraram efeito dose-resposta na associação entre a prática alimentar na infância e a obesidade avaliaram o aleitamento materno exclusivo, porém não se tem um consenso sobre qual mecanismo estaria envolvido nesse efeito (Von Kries, 1999; Gilmann, 2001; Liese, 2001).

Tarefa nada fácil é comparar o resultado do presente estudo com a literatura publicada, não só pela existência de resultados contraditórios como também pela grande heterogeneidade dos estudos, tanto em termos de delineamento quanto de diferentes definições para a obesidade e aleitamento materno, controle de variáveis de confusão e a idade da medida do desfecho - obesidade, além das diferenças socioculturais dos países onde foram realizados os estudos.

Os resultados do nosso estudo são consistentes com o estudo de Kramer (1981) realizado no Canadá com adolescentes de 12 a 18 anos de idade. Nesse estudo, encontrou-se um odds ratio bruto de 2,25 para a obesidade em crianças que nunca 
receberam aleitamento e esse risco permaneceu significativo após controle de variáveis de confusão (raça, classe social, ordem de nascimento, IMC dos pais). Kramer sugere em seu trabalho que a duração do aleitamento materno seria menos importante do que o aleitamento materno durante as primeiras semanas ou meses de vida, uma vez que esse período seria o mais crítico para a expressão do efeito protetor da amamentação. Essa suposição reforça o resultado do presente estudo no qual se detectou uma grande diferença no risco de obesidade $(\mathrm{OR}=2,06$ e IC $95 \%=1,02-4,16)$ para crianças que nunca receberam aleitamento materno.

Elliot (1997), estudando adolescentes americanos, concluiu que crianças que nunca receberam aleitamento materno ou que receberam por dois meses ou menos mais do que duplicaram a chance de se tornarem obesas na adolescência $(\mathrm{OR}=2,4)$, porém tal achado somente foi estatisticamente significativo para adolescentes de baixo nível socioeconômico.

Outro estudo concordante com nossos achados é o de Tosckhe (2002), realizado na República Tcheca. Neste estudo, que avaliou o efeito do aleitamento materno no risco de obesidade em crianças e adolescentes com idades entre 6 e 14 anos, encontrou-se uma odds ratio de 0,80 (IC $95 \%=0,66$ - 0,96) para a obesidade em crianças que receberam aleitamento materno quando comparados aos que nunca receberam. $O$ fato de o referido autor também não ter avaliado o aleitamento exclusivo - assim como nosso estudo - e ter avaliado algumas das potenciais variáveis de confusão que também avaliamos, fortalece os nossos resultados. Tosckhe também não encontrou efeito dose-resposta significativo na associação entre a prevalência de obesidade e a duração do aleitamento materno. 
Por outro lado, $\mathrm{Li}$ (2003), em estudo transversal retrospectivo realizado na Inglaterra, no qual foram estudados crianças e adolescentes de 4 a 18 anos- faixa etária que abrange as idades contempladas em nosso estudo- não encontrou associação significativa entre obesidade e prática alimentar na infância. Destaque-se que esse estudo também não avaliou o efeito do aleitamento exclusivo e tem como uma importante limitação o fato de não ter controlado o IMC materno, uma importante variável que, em alguns estudos, foi associada tanto à obesidade infantil quanto ao aleitamento materno, conforme será discutido mais adiante. No referido estudo, utilizouse, alternativamente, o IMC do pai ou da mãe, sendo que as evidencias de associação indicam que a obesidade materna é um importante fator de risco para a obesidade infantil.

Poucos estudos prévios avaliaram o efeito protetor do aleitamento por períodos prolongados, ou seja, por mais de um ano, como testado em nosso estudo. Dois estudos que testaram esse efeito encontraram uma maior proteção da amamentação contra o sobrepeso e obesidade. Von Kries et al (1999) encontraram uma redução de 57\% no risco de sobrepeso em crianças de 5 a 6 anos que receberam aleitamento materno por um ano ou mais quando comparadas às que nunca receberam. Liese (2001) encontrou um efeito ainda maior: $71 \%$ de redução no risco de sobrepeso. Esses achados são consistentes com o achado do nosso estudo que verificou um risco de obesidade de, aproximadamente, 3 vezes para as crianças e adolescentes que nunca receberam leite materno em relação as que receberam por 1 ano ou mais, sendo esse risco bem próximo da significância estatística $(\mathrm{OR}=2,73$; IC $95 \%=0,98-7,64)$. 
É interessante destacar que Von Kries (1999), ao avaliar o efeito da dieta, encontrou uma relação inversa entre o consumo de produtos lácteos com alto teor de gordura e o sobrepeso e obesidade, provavelmente refletindo causalidade reversa, ou seja, crianças obesas ou com sobrepeso poderiam estar evitando o consumo desses produtos.

Outros estudos que levaram em conta o padrão alimentar atual da criança (Victora, 2003; Gillman, 2001) constataram que o controle do mesmo não alterava significativamente a associação entre aleitamento materno na infância e a obesidade em idades posteriores. De fato, o resultado da meta-análise realizada por Owen (2005) sugere que o efeito protetor do aleitamento materno no início da vida se estende ao longo dos anos, sendo independente do padrão alimentar e de atividade física no decorrer da vida.

Finalizando nossa discussão, de forma a controlar o maior número possível de potenciais variáveis de confusão, procurou-se levar em conta o efeito do padrão alimentar atual da criança. Entretanto, rigorosamente, não haveria a necessidade deste controle, uma vez que o padrão alimentar poderia ser um dos mecanismos por meio dos quais a amamentação poderia atuar como fator protetor contra a obesidade na idade escolar. 


\section{CONCLUSÕES}

$\mathrm{O}$ resultado da presente pesquisa sugere que não existe uma simples resposta para a questão do efeito protetor do aleitamento contra obesidade em crianças e adolescentes e que este assunto ainda apresenta controvérsias.

De fato, o que se encontrou no estudo realizado em amostra de estudantes do ensino fundamental de uma escola particular de alto nível socioeconômico foi um risco significativamente maior de obesidade para crianças que nunca receberam aleitamento materno, não se podendo afirmar, entretanto, que este maior risco realmente reflita um efeito protetor do aleitamento materno relacionado a propriedades do leite humano e não diferenças comportamentais entre as mães que amamentam e não amamentam seus filhos.

Mais estudos são necessários, principalmente estudos longitudinais que controlem todas as variáveis que possam estar relacionadas tanto ao aleitamento materno quanto à obesidade. Destaca-se a necessidade de estudos que possam aferir com mais precisão a duração do aleitamento materno e que incluam o aleitamento materno exclusivo como variável exposição e que também controlem de forma mais eficaz os atributos comportamentais maternos.

De qualquer forma, baseado no seu imenso beneficio tanto para a criança quanto para a mãe e para a sociedade, o aleitamento exclusivo deve ser recomendado até o 6 mês de vida. As ações de promoção, proteção e incentivo ao aleitamento materno devem ser cada vez mais estimuladas. 


\section{REFERÊNCIAS BIBLIOGRÁFICAS}

Agostini C; Riva E; Scaglioni S; Marangoni F;Radaelli G; Giovannini M. Dietary fats and cholesterol in Italian infants and children. Am J Clin Nut 2000; 72 (suppl):1384s$91 \mathrm{s.}$

American Diabetes Association. Type 2 diabetes in children and adolescents. Pediatrics 2000,105:671-680.

Anjos LA, Rugani IR, Engstron EM, Azevedo AM. Crescimento e estado nutricional em amostra probabilística de escolares no município do Rio de Janeiro, 1999. Cad. Saúde Pública 2003, Rio de Janeiro, 19 (sup 1): S171-S179.

Arenz S, Ruckerl R, Koletzko B, Von Kries R. Breast feeding and childhood obesity - a systematic review. Int J Obes 2004, 28:1247-1256

Aye T; Levitsky LL Type 2 diabetes: an epidemic disease in childhood. Curr. Opin Pediatr 2003,15:411-415.

Bergmann KE, Von Kries R, Bohm O, Ritcher R, Dudenhausen JW, Wahn U. Early determinants of childhood overweight and adiposity in a birth cohort study: role of breast feeding. Int J Obes 2003, 27:162-172.

Bertini G et al. Maternal education and the incidence and duration of breast feeding: a prospective study. Pediatr Gastroenterol Nutr 2003;Oct;37(4):447-52. Bogen DL, Hanusa BH, Whiataker RC. The effect of breast-feeding with and whithout formula use on the risk of obesity at 4 years of age.Obes Res 2004; 12(9):1527-1535, 2004. 
Butte NF. The role of breast feeding in obesity. Pediatr Clin of North Am 2001, v.48, n. 1 .

Charney E, Goodman HC, Mcbride M, Lyon B, Pratt R. Do chubby infants become obese adults? N Engl J of Med 1976; n.1; v .295.

Desai M, Hales CN, Zhang J, Petry CJ, Lucas A. Programming of hepatic insulin sensitive enzymes in offspring of rat dams fed a protein-restricted diet. Am J Physiol $1997 ; 272: 1083-90$.

Dewey KG et al. Infant self regulation of breast milk intake. Acta Paediatr Scand 1986; 75:893-898.

Dewey KG , Heinig MJ, Nommsen LA, Peerson JM, Lonnerdal B. Energy and protein intakes of breast fed and formula fed infants during the first year of life and their association with growth velocity: the DARLING Study. Am J Clin Nutr 1993, v.58:152-61.

Eaton Evans J, Dugdale AE. Recall by mothers of the birth weight and feeding of their children. Hum Nutr 1986; 40a:171-5

Elliot GK, Kjolhede CL, Gournis E, Rasmussen KM. Duration of breastfeeding associated with obesity during adolescence. Obes Res 1997, v.5, n.6.

Eriksson JG , Forsen T, Tuomilchto J, Osmond C, Barker DJP. Early growth and coronary heart disease in later life: longitudinal study. BMJ 2001; 822:949-953.

Freedman DS et al. The relation of overweight to cardiovascular risk factors among children and adolescents: the Bogalusa Heart Study. Pediatrics 1999; 103:1175-1182.

French SA et al. Self steem and obesity in children and adolescents: a literature review. Obes Res 1995; 3: 479-490 
Gilmann MW et al. Risk of overweight among adolescents who were breastfed as infants. JAMA 2001, 285(19):2461-2467.

Gortmaker SL; Dietz WH; Sobol AM; Wehler CA. Increasing pediatric obesity in the United States. Am J Dis Child 1987; vol. 141:533-540.

Haaga J. Reliability of retrospective survey data on infant feeding. Demography 1988; 25:307-14.

Hall B. Changing composition of human milk and early development of appetite control. Lancet 1975; 1:779-81.

Hanl PJ; Lomerdal B. Serum leptin concentration in infants: effects of diet, sex and adiposity. Am J Clin Nutr 2000, 72(2): 484-489.

Hediger ML, Overpeck MD, Kuczmarski RJ, Ruan WJ. Association between infant breastfeeding and overweight in young children. JAMA 2001; 285 (19):2453-2460.

Hilson JA, Rasmussen KM, Kjolhede CL. High prepregnant body mass index is associated with poor lactation outcomes among white, rural women independent of psychosocial and demographic correlates. J Hum Lact 2004; 20:18-19.

Hypponen E, Virtanen S, Kenward MG et al. Obesity, increased linear growth and risk of type I diabetes in children. Diabetes Care 2000; 23:1755-60.

Kahn R. Type 2 diabetes in children and adolescents. Diabetes Care 2000; 23(3):381389.

Kark JD et al. Validity of maternal reporting of breastfeeding history and the association with blood lipids in 17 years olds in Jerusalem. J Epidemiol Commun Health 1984; 38:218-25. 
Kelder SH, Perry CL, Klepp KI, Lytle LL. Longitudinal tracking of adolescence smoking, physical activity and food choice behavior. Am J Public Health 1994;84:1121-1126.

Kramer MS. Do breast feeding and delayed introduction of solid foods protect against subsequent obesity? J Pediatr 1981; 98:883-887.

Kummer CS et al. Evolução do padrão de aleitamento materno. Rev Saúde Pública $2000 ; 34$ (2): 143-48.

Launer JL et al. Maternal recall of infant feeding events is accurate. J Epidemiol Community Health 1992; 46:203-206.

Li L, Parsons TJ, Power G. Breast feeding in childhood: cross sectional study. BMJ 2003 oct, v. 327.

Li R, Jewell S; Grummer Strawn. Maternal obesity and breast feeding practices. Am J Clin Nut 2003; 77:931-6.

Liberatos P, Link BG, Kelsy JL. The measurement of social class in epidemiology. Epidemiol Rev 1988; 10: 87-121

Liese AD, Hirsch T, Mutius E Von, Leupold W, Weiland SK. Inverse association of overweight and breastfeeding in 9 to 10 year old children in Germany. Int J Obes 2001; 25:1644-1650.

Lucas A, Blackburn AM, Aynsley-Green A. Breast vs bottle: endocrine responses are different with formula feeding. The Lancet 1980; june, n.14.

Macedo, M. E.; Trigueiros, D.; Freitas, F. Prevalence of high blood pressure in children and adolescents. Rev Port Cardiol. 1997; 16(11):27-30.

Mallory GB, Fiser DH, Jackson R. Sleep associated breathing disorder in obese children and adolescents. J Pediatr 1989; 115:892:7. 
Martin MM, Martin ALA. Obesity, hyperinsulinism and diabetes mellitus in childhood. J Pediatr 1973; 82:192-201.

Martorell R, Stein AD, Schroder DG. Early nutritional and later adiposity. J Nutr 2001; $131(3): 874 s-880 s$.

Monteiro CA, Benicio MHDA, Conde WL, Popkin B. Shifting obesity trends in Brazil. Eur J Clin Nut 2000; 54:342-6.

Monteiro CA, Wang Y, Popkin BM. Trends of obesity and overweight in older children and adolescents in United States, Brazil, China and Russia. Am J Clin Nut 2002; 75:971-7.

Nommsen LA, Lovelady CA, Heinig MJ et al. Determinants of energy, protein, lipid and lactose concentration in human milk during the first 12 months of lactation: the DARLING study. Am J Clin Nutr 1991; 53:457-465.

Ong KK, Ahmed ML, Emmett PM, Preece MA, Dunger DB. Association between postnatal catch-up growth and obesity in childhood: prospective cohort study. BMJ 2000; 320: 967-971.

Owen CG, Martin RM, Whincup PH, Smith DG. Effect of infant feeding on the risk of obesity across life course: a quantitative review of published evidence. Pediatrics 2005; $115 ; 1367-1377$.

Pinhas Hamiel O, Dolon LM, Daniels SR, Standford D, Khoury PR, Zeither P. Increased incidence of non insulin dependent diabetes mellitus among adolescents. J Pediatr 1996; 128:608:15.

Popkin BM, Caballero B. The nutritional Transition: diet and disease in the developing World. Academic Press, London, 2002.

Power C, Lake JK, Cole T. Measurement and long term health risks of child and adolescents fatness. Int J Obes Metab Disord 1997; 21:507-526. 
Proctor MH et al. Television Viewing and change in body fat from prescholl to early adolescence: The Framingham Children's Study. Int J Obes 2003; 27, 827:833.

Reilly JJ, Methven E et al. Health consequences of obesity. Arch Dis Child 2003; 88:748-752.

Riley DJ, Santiago TV, Edlmon NH. Complication of obesity hipoventilation syndrome in childhood. Am J Dis Child 1976; 130:671-4.

Rolland-Cachera MF, Deheenger $\mathrm{M}$ et al. Influence of macronutrients on adiposity development: a follow up study. Int J Obes 1995 ; 19:573-578.

Ronnemaa T, Knip M, Lautala P et al. Serum insulin and other cardiovascular risk indicators in children, adolescents and young adults. Ann Med 1991; 23:67-72.

Rosembloom AL et al. Emerging epidemic of type 2 diabetes in Youth. Diabetes Care $1999 ; 22: 345-354$.

Scaglioni S, Agostini C et al. Early macronutrient intake and overweight at five years old. Int J Obes 2000; 24:777-781.

Serdula MK; Ivery D; Coates RJ; Freedman DS; Williamsson DF; Byers T. Do obese children become obese adults. A review of the literature. Prevent Méd 1993; 22:167177.

Singhal A et al. Early nutrition and leptin concentrations in later life. Am J Clin Nutr 2002; 75:993-999.

Smoak CG; Burke GL; Webber SL; Harsha DW; Srinivasan SR; Berenson GS. Relation of obesity to clustering of cardiovascular disease risk factors in children and young adults. The Bogalusa Heart Study. Am J Epidemiol 1987; vol 125, n.3.

Steinberger J, Morehead C, Katch V, Rocchin AP. The relationship between insulin resistance and abnormal lipid profile in obese adolescents. J Pediatr 1995; 126:6910-1. 
Stettler N, Zemel BS, Kumanyika S, Stallings VA. Infant weight gain and childhood overweight status in a multicenter cohort study. Pediatrics 2002; v.109, n.2, feb.2002.

Strauss RS, Pllack HA. Social marginalization of overweight children. Arc Pediatr Adolesc Med aug 2003, v.157:746-752.

Thorpe EL et al. Childhood Obesity in New York City Elementary School Students. Am J Public Health 2004, v. 94; 9:1496-1500.

Toschke AM, Vignerova J, Lhotska L,Osancova K, Koletzo B, Von Kries R. Overweight and obesity in 6-to-14 year-old Czech children in 1991: protective effect of breast feeding. J Pediatr 2002; v.141.n.6.

Uauy R; Mize CE; Castillo Duran C. Fat intake during childhood: metabolic responses and effects on growth. Am J Clin Nutr 2000; 72(suppl):1354s-60s.

Venâncio S, Escuder MM, Kitoco P, Rea M, Monteiro CA. Frequência e determinantes do aleitamento materno em municípios do Estado de São Paulo. Rev Saúde Pública 2002; 36(3): 313-18.

Victora C, Barros F, Lima R, Horta B, Wells J. Antropometry in body composition of 18 year old men according to duration of breastfeeding: birth cohort study from Brazil. BMJ 2003; v.327, oct.

Von Kries R, Koletzo B et al. Breast feeding and obesity: cross sectional study. BMJ 1999; v.319, jul.

Ward $\mathrm{M}$ et al. Infant feeding: factors affecting initiation, exclusivity and duration. Ir Med J 2004; Jul-Aug; 97(7):197-9.

Whitaker RC et al. Predicting obesity in young adulthood from childhood and parental obesity. N Engl J Med 1997, v.37,n.13. 
World Health Organization. Sample size determination in health studies: a practical manual. Lwang SK, Lemeshow; Geneva 1991.

World Health Organization. Physical Status: uses and interpretation of antropometry. WHO Technical Report Series, 954, Geneva, 1995.

World Health Organization. Diet, Nutrition and the prevention of chronic diseases. WHO Technical Report Series, 916, Geneva, 2003.

World Health Organization. Obesity: preventing and managing the global epidemic. WHO Technical Report Series, 894, Geneva, 2003.

Zive MM et al. Infant feeding practices and adiposity in 4 year old anglo and Mexican Americans. Am J Clin Nutr 1992; 55:1104-08. 
ANEXO 1 


\section{(1) \\ Universidade de Sxo Paulo \\ Faculdade de Sańde Pública \\ COMITE DE FTICA-COEP}

Av. Dr. Amnido, 715 - CEP $01246-944$ - S80 Pando - Brasil

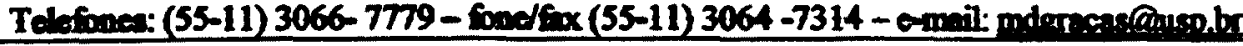

\section{OLCOJP/209/23}

02 de dezembro de 2003

Polo presente, informo que o Comitê de Ética em Pesquisa da Faculdade de Sarde PCblica da Universidade de Sao Paulo-COEP, analison e aprovou, de acordo com os requisitos da Resolucăo CNS/196/96, o Protocolo de Pesquisa n` 1029, intitulado: "PODERIA O ALETTAMENTO MATERNO REDUZIR O RISCO DE OBESIDADE EM ADOEL SCENTES?", apresentado pela pesquisadora Renata Scanferla Siqueira.

Atenciosamente,

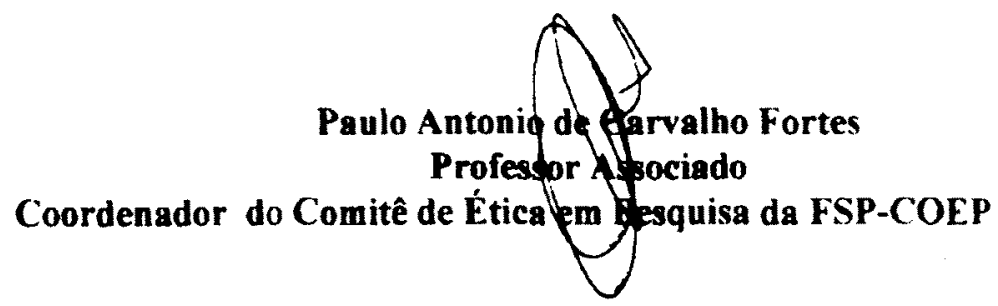


ANEXO 2 
TERMO DE CONSENTIMENTO LIVRE E ESCLARECIDO

Esta pesquisa realizada pela Faculdade de Saúde Pública da Universidade de São Paulo e tem como objetivo avaliar o estado nutricional e os padrões de alimentação de estudantes na cidade de São Paulo.

A pesquisa envolve a tomada de medidas de peso, altura e dobras cutâneas que foi feita junto aos professores de Educação Física, conforme rotina do Colégio Batista.

Caso o responsável não concorde com a participação de seu(a) filho(a), os dados obtidos na avaliação física, não serão utilizados.

Além da avaliação física, será necessário o preenchimento de um breve questionário que segue anexo. Esse questionário deverá ser entregue a Secretaria do curso, até o dia 05 de março de 2004.

A participação é voluntária, todas as informações serão sigilosas e a qualquer momento, - responsável poderá desistir da participação do seu(a) filho(a), basta para isso, entrar em contato com a pesquisadora responsável, RENATA SCANFERLA SIQUEIRA, pelo tel. 30667701 ou no seguinte endereço: Faculdade de Saúde Pública, Departamento de Nutrição . Avenida Dr. Arnaldo, 715, $2^{\circ}$ andar - São Paulo- SP. Cep. 01246-904.

Autoriza a participação do seu(a) filho)a) na pesquisa.

$(\quad) \sin$

( ) Năo

Nome do aluno série

Assinatura do responsável 
ANEXO 3 


\section{Padrões de alimentação e nutrição de escolares da cidade de São Paulo}

Esse questionário faz parte de um estudo do Núcleo de Pesquisas Epidemiológicas em Nutrição e Saúde da Universidade de São Paulo - NUPENS/USP.

Este questionário deve ser preenchido exclusivamente pela mãe/responsável do aluno(a)

Todas as questōes que mencionarem a expressāo "seu filho" se referirão $a(0)$ aluno(a) acima mencionado(a).

$>$ Para preencher use lápis ou caneta. Se a sra. não quiser responder alguma pergunta, deixe em branco.

Todas as informaçōes prestadas pela sra. serão mantidas em sigilo e serão utilizadas apenas para fins do presente estudo.

Obrigado por sua colaboração! 


\section{Qual é a data de nascimento do seu filho?}

$$
\overline{\text { dia }}^{\prime} \overline{\mathrm{m}}_{\mathrm{ês}}^{\prime}-\overline{\text { ano }}^{\prime}
$$

2. Qual foi o peso do seu filho ao nascer?

$$
\text { 一 - - - } \mathrm{kg}
$$

$\square$ não lembra/não sabe

3. Qual foi o comprimento do seu filho ao nascer?

$\square$ não lembra/não sabe

4. O seu filho nasceu:

$$
\begin{aligned}
& \text { 口no tempo certo } \\
& \text { antes da data prevista (prematuro) } \\
& \text { depois do tempo }
\end{aligned}
$$

$\square$ não lembra/não sabe

\section{O seu filho mamou no peito?}

\section{$\square \operatorname{sim}$}

$\square$ não/nunca $\rightarrow$ (pule para questão 7)

6. Até que idade seu filho mamou no peito?
$\square$ menos de 1 mês
$\square 1$ mês
$\square 2$ meses
$\square 3$ meses
$\square 4$ meses
$\square 5$ meses
$\square 6$ meses
$\square 7$ meses
$\square 8$ meses
$\square 9$ meses
$\square 10$ meses
$\square 11$ meses
ㅁ 12 meses
$\square$ entre 13 e 18 meses
$\square$ entre 19 e 24 meses
$\square$ mais que 2 anos
$\square$ não lembra/não sabe

7. Que idade seu filho tinha quando tomou pela primeira vez outro leite que não o leite de peito (qualquer outro leite)?

$\square$ menos de 1 mês

$\square 1$ mês

$\square 2$ meses

$\square 3$ meses

$\square 4$ meses

$\square$ meses

$\square 6$ meses

$\square 7$ meses

$\square 8$ meses

9 meses

$\square 10$ meses

$\square 11$ meses

$\square 12$ meses

$\square$ entre 13 e 18 meses

$\square$ entre 19 e 24 meses

$\square$ mais que 2 anos

$\square$ não lembra/não sabe

8. Qual era o tipo desse leite?

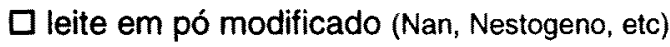

$\square$ leite em pó integral (Ninho, etc)

$\square$ leite fluido pasteurizado

$\square$ leite longa vida

$\square$ outro tipo de leite:

$\square$ não lembra/não sabe

9. Com que idade seu filho comeu a primeira papa/comida de sal?

$\square$ menos de 1 mês

$\square 1$ mês

$\square 2$ meses

ㅁ 3 meses

$\square 4$ meses

$\square 5$ meses

$\square 6$ meses

$\square 7$ meses

$\square 8$ meses

$\square 9$ meses

$\square 10$ meses

$\square 11$ meses

$\square 12$ meses

$\square$ entre 13 e 18 meses

$\square$ entre 19 e 24 meses

$\square$ mais que 2 anos

$\square$ não lembra/não sabe 
10. Antes de completar um ano seu filho foi internado alguma vez?

\section{$\square \operatorname{sim}$ \\ $\square$ não $\rightarrow$ (pule para a questão 12)}

$\square$ não lembra/não sabe $\rightarrow$ (pule para questão 12)

11. Que idade seu filho tinha quando foi internado pela primeira vez?

_

12. Seu filho tem asma ou bronquite?
$\square \operatorname{sim}$
$\square$ não

$\square$ não sabe

13. Na sua opinião, o seu filho está:
$\square$ muito magro
$\square$ magro
$\square$ normal
$\square$ gordo
$\square$ muito gordo

14. Na sua opinião, a alimentação do seu filho é:
$\square$ bem variada
$\square$ variada
$\square$ pouco variada
$\square$ muito pouco variada
$\square$ não sabe

15. Em relação a quantidade, o seu filho come:
$\square$ muito pouco
$\square$ pouco
$\square$ normal
$\square$ muito
$\square$ demais
$\square$ não sabe

16. Seu filho come de tudo ou é enjoado para comer?

\section{$\square$ come de tudo}

é enjoado para comer

$\square$ mais ou menos

$\square$ não sabe
17. Em uma semana comum, incluindo sábado e domingo, quantos dias por semana o seu filho toma café da manhã?

Café da manhã:

pelo menos um alimento sólido e uma bebida.
$\square$ todos os 7 dias da semana
$\square 6$ dias por semana
$\square 5$ dias por semana
4 dias por semana
$\square 3$ dias por semana
$\square 2$ dias por semana
$\square 1$ dia por semana
$\square$ nunca ou raramente
$\square$ não sabe

18. Em uma semana comum, incluindo sábado e domingo, quantos dias por semana o seu filho troca comida de sal por lanche?
$\square$ todos os 7 dias da semana
$\square 6$ dias por semana
$\square 5$ dias por semana
$\square 4$ dias por semana
$\square 3$ dias por semana
$\square 2$ dias por semana
$\square 1$ dia por semana
$\square$ nunca ou raramente
$\square$ não sabe

19. Em uma semana comum, incluindo sábado e domingo, quantos dias por semana o seu filho come vendo televisão?
$\square$ todos os 7 dias da semana
$\square 6$ dias por semana
$\square 5$ dias por semana
$\square 4$ dias por semana
$\square 3$ dias por semana
$\square 2$ dias por semana
$\square 1$ dia por semana
$\square$ nunca ou raramente
$\square$ não sabe

20. Em uma semana comum, incluindo sábado e domingo, quantos dias por semana o seu filho faz pelo menos uma refeição com a familia?
$\square$ todos os 7 dias da semana
$\square 6$ dias por semana
$\square 5$ dias por semana
$\square 4$ dias por semana
$\square 3$ dias por semana
$\square 2$ dias por semana
$\square 1$ dia por semana
$\square$ nunca ou raramente
$\square$ não sabe 
21. Em uma semana comum, incluindo sábado e domingo, quantos dias por semana o seu filho come feijão?
$\square$ todos os 7 dias da semana
$\square 6$ dias por semana
$\square 5$ dias por semana
$\square 4$ dias por semana
$\square 3$ dias por semana
$\square 2$ dias por semana
$\square 1$ dia por semana
$\square$ nunca ou raramente

$\square$ não sabe

22. Em uma semana comum, incluindo sábado e domingo, quantos dias por semana o seu filho come batata frita?

$\square$ todos os 7 dias da semana

$\square 6$ dias por semana

$\square 5$ dias por semana

$\square 4$ dias por semana

$\square 3$ dias por semana

$\square 2$ dias por semana

$\square 1$ dia por semana

$\square$ nunca ou raramente

\section{$\square$ não sabe}

23. Em uma semana comum, incluindo sábado e domingo, quantos dias por semana o seu filho come salada crua (alface, tomate, etc)?
$\square$ todos os 7 dias da semana
$\square 6$ dias por semana
$\square 5$ dias por semana
$\square 4$ dias por semana
$\square 3$ dias por semana
$\square 2$ dias por semana
$\square 1$ dia por semana
$\square$ nunca ou raramente

\section{$\square$ não sabe}

24. Em uma semana comum, incluindo sábado e domingo, quantos dias por semana o seu filho come hambúrguer?

$\square$ todos os 7 dias da semana

$\square 6$ dias por semana

$\square 5$ dias por semana

$\square 4$ dias por semana

$\square 3$ dias por semana

$\square 2$ dias por semana

$\square 1$ dia por semana

$\square$ nunca ou raramente

$\square$ não sabe
25. Em uma semana comum, incluindo sábado e domingo, quantos dias por semana o seu filho come frutas?

$\square$ todos os 7 dias da semana

$\square 6$ dias por semana

$\square$ dias por semana

$\square 4$ dias por semana

$\square 3$ dias por semana

$\square 2$ dias por semana

$\square 1$ dia por semana

$\square$ nunca ou raramente

$\square$ não sabe

26. Em uma semana comum, incluindo sábado e domingo, quantos dias por semana o seu filho come cachorro quente?

$\square$ todos os 7 dias da semana

$\square 6$ dias por semana

$\square 5$ dias por semana

$\square 4$ dias por semana

$\square 3$ dias por semana

$\square 2$ dias por semana

$\square 1$ dia por semana

$\square$ nunca ou raramente

$\square$ não sabe

27. Em uma semana comum, incluindo sábado e domingo, quantos dias por semana o seu filho come legumes ou verduras cozidos?

$\square$ todos os 7 dias da semana

$\square 6$ dias por semana

ㄷ 5 dias por semana

$\square 4$ dias por semana

$\square 3$ dias por semana

$\square 2$ dias por semana

$\square 1$ dia por semana

$\square$ nunca ou raramente

$\square$ não sabe

28. Em uma semana comum, incluindo sábado e domingo, quantos dias por semana o seu filho come salgadinhos (do tipo que se compra em "pacotinhos")?

$\square$ todos os 7 dias da semana

$\square 6$ dias por semana

$\square 5$ dias por semana

$\square 4$ dias por semana

$\square 3$ dias por semana

$\square 2$ dias por semana

$\square 1$ dia por semana

$\square$ nunca ou raramente

$\square$ não sabe 
29. Em uma semana comum, incluindo sábado e domingo, quantos dias por semana o seu filho come salgados (coxinha, quibe, pastel, etc)?

\section{$\square$ todos os 7 dias da semana}

$\square 6$ dias por semana

$\square 5$ dias por semana

$\square 4$ dias por semana

$\square 3$ dias por semana

- 2 dias por semana

$\square 1$ dia por semana

$\square$ nunca ou raramente

$\square$ não sabe

30. Em uma semana comum, incluindo sábado e domingo, quantos dias por semana o seu filho come biscoitos doces recheados?

$\square$ todos os 7 dias da semana

$\square 6$ dias por semana

$\square 5$ dias por semana

$\square 4$ dias por semana

$\square 3$ dias por semana

$\square 2$ dias por semana

$\square 1$ dia por semana

$\square$ nunca ou raramente

$\square$ não sabe

31. Em uma semana comum, incluindo sábado e domingo, quantos dias por semana o seu filho toma refrigerante?

todos os 7 dias da semana

$\square 6$ dias por semana

$\square 5$ dias por semana

$\square 4$ dias por semana

$\square 3$ dias por semana

$\square 2$ dias por semana

$\square 1$ dia por semana

$\square$ nunca ou raramente

$\square$ não sabe

32. Em uma semana comum, incluindo sábado e domingo, quantos dias por semana o seu filho bebe leite?

$\square$ todos os 7 dias da semana

$\square 6$ dias por semana

$\square 5$ dias por semana

$\square 4$ dias por semana

$\square 3$ dias por semana

$\square 2$ dias por semana

$\square 1$ dia por semana

$\square$ nunca ou raramente

$\square$ não sabe
33. O seu filho faz ou pratica algum tipo de esporte ou exercício físico?

Exemplos: jogar futebol, vôlei, handebol, fazer ginástica, dança/balé, judô, capoeira, natação, etc.

$\square \operatorname{sim}$

$\square$ não $\rightarrow$ (pule para questão 36 )

34. Em uma semana comum, incluindo sábado e domingo, quantos dias por semana o seu filho pratica esporte ou exercício físico?

$\square 1$ dia por semana

$\square 2$ dias por semana

$\square 3$ dias por semana

$\square 4$ dias por semana

5 dias por semana

$\square 6$ dias por semana

$\square 7$ dias por semana

$\square$ não sabe

35. No dia em que seu filho pratica esporte ou exercício físico, quanto aproximadamente dura esta atividade?

$\square$ menos de meia hora por dia

$\square$ meia hora por dia

1 hora por dia

2 horas por dia

3 horas por dia

4 ou mais horas por dia

$\square$ não sabe

36. Seu filho costuma assistir TV?

$\square$ sim, todos os dias

$\square$ sim, quase todos os dias

$\square$ só final de semana $\rightarrow$ (pule para questão 38 )

$\square$ só de vez em quando $\rightarrow$ (pule para questão 38 )

$\square$ não $\rightarrow$ (pule para questão 38 )

$\square$ não sabe $\rightarrow$ (pule para 38 )

37. Quantas horas por dia o seu filho costuma assistir TV?

$\square$ menos de 1 hora

1 hora

2 horas

$\square 3$ horas

4 horas

5 horas

$\square 6$ horas ou mais

$\square$ não sabe

38. Seu filho costuma jogar videogame ou jogos no computador?

$\square$ sim, todos os dias

$\square$ sim, quase todos os dias

$\square$ só final de semana $\rightarrow$ (pule para questão 40)

$\square$ só de vez em quando $\rightarrow$ (pule para questão 40 )

$\square$ não $\rightarrow$ (pule para questão 40 )

$\square$ não sabe $\rightarrow$ (pule para questão 40 ) 
39. Quantas horas por dia o seu filho costuma jogar videogame ou jogos no computador?

$\square$ menos de 1 hora

$\square 1$ hora

$\square 2$ horas

$\square 3$ horas

$\square 4$ horas

$\square$ horas

$\square 6$ horas ou mais

$\square$ não sabe

40. Seu filho costuma utilizar computador para fazer lições, pesquisa na Internet, etc?

$\square \operatorname{sim}$

$\square$ não $\rightarrow$ (pule para questão 42)

41. Quantas horas por dia o seu filho costuma utilizar computador pra fazer liçōes, pesquisas na Internet, etc?

$\square$ menos de 1 hora

$\square 1$ hora

$\square 2$ horas

口 3 horas

$\square 4$ horas

$\square$ horas

$\square 6$ horas ou mais

$\square$ não sabe

42. Qual é a idade da sra.?

- (anos completos)

43. A sra. fumou durante a gravidez desse seu filho?

$\square \operatorname{sim}$

口não

44. A sra. fuma atualmente?

$\square \operatorname{sim}$

$\square$ não

45. A sra. trabalhava fora de casa quando engravidou desse seu filho?

$\square \operatorname{sim}$

$\square$ não $\rightarrow$ (pule para questão 48)

46. A sra. voltou a trabalhar fora de casa depois que o seu filho nasceu?

$\square \operatorname{sim}$

$\square$ não $\rightarrow$ (pule para questão 48)

47. Quantos meses ele tinha quando a sra. voltou a trabalhar?

meses
48. No momento a sra. está trabalhando fora de casa?

$\square \operatorname{sim}$

$\square$ não $\rightarrow$ (pule para questão 51)

49. Quantos dias por semana a sra. trabalha fora de casa?

_ dias

50. Quantas horas por dia a sra. trabalha fora de casa?

- horas

51. Qual é o total de filhos que a sra. tem?

$\square 1$ filho $\rightarrow$ (pule para questão 54 )
$\square 2$ filhos
$\square 3$ filhos
$\square 4$ filhos
$\square 5$ filhos ou mais

52. Esse seu filho é o mais velho?

$\square \operatorname{sim} \rightarrow$ (pule para questão 54 )
$\square$ não

53. Quantos irmãos mais velhos ele tem?

$\square 1$ irmão mais velho

$\square 2$ irmãos mais velhos

$\square 3$ irmãos mais velhos

$\square 4$ irmãos mais velhos

$\square 5$ ou mais irmãos mais velhos

54. Por favor, informe a escolaridade da sra.:

$\square 1^{\circ} \mathrm{grau}$ incompleto

$\square 1^{\circ}$ grau completo

$\square 2^{\circ}$ grau incompleto

$\square 2^{\circ}$ grau completo

$\square$ curso superior incompleto

$\square$ curso superior completo

$\square$ pós-graduação

$\square$ nunca estudou

$\square$ não lembra/não sabe

55. A sra. é a chefe da sua familia?

$$
\begin{aligned}
& \square \operatorname{sim} \rightarrow \text { (pule para questão } 57 \text { ) } \\
& \square \text { não }
\end{aligned}
$$

56. Por favor, informe a escolaridade do chefe da sua família?

$\square 1^{\circ} \mathrm{grau}$ incompleto

$\square 1^{\circ}$ grau completo

$\square 2^{\circ}$ grau incompleto

$\square 2^{\circ}$ grau completo

$\square$ curso superior incompleto

$\square$ curso superior completo

$\square$ pós-graduação

$\square$ nunca estudou

nāo lembra/não sabe 
57. Quanto tempo faz que a sra. se pesou pela última vez?

\section{$\square$ menos de 1 semana}

$\square$ menos de 1 mês

$\square$ menos de 3 meses

$\square$ menos de 6 meses

$\square$ há seis meses ou mais

$\square$ nunca se pesou

$\square$ não lembra/não sabe

58. Quanto a sra. pesa ?

$-\ldots, \ldots \mathrm{kg}$

$\square$ não sabe informar

$\square$ não quer informar

59. Qual é a altura da sra.?

$\mathrm{cm}$

$\square$ não sabe informar

$\square$ não quer informar

60. A sra. está satisfeita com o seu peso?
$\square \operatorname{sim}$
$\square$ mais ou menos
$\square$ não

61. A sra. fazendo alguma dieta?
$\square \operatorname{sim}$
$\square$ não

62. O sra. faz ou pratica algum tipo de esporte ou exercicio físico?

\section{Exemplos:}

caminhada, ginástica, dançaßbalé, natação, etc.
$\square \operatorname{sim}$
$\square$ não $\rightarrow$ (pule para questão 65)

63. Em uma semana comum, incluindo sábado e domingo, quantos dias por semana a sra. pratica esporte ou exercício físico?

$\square 1$ dia por semana

$\square 2$ dias por semana

$\square 3$ dias por semana

$\square 4$ dias por semana

$\square 5$ dias por semana

$\square 6$ dias por semana

$\square 7$ dias por semana

$\square$ não sabe
64. No dia em que a sra. pratica esporte ou exercício físico, quanto tempo aproximadamente dura esta atividade?

$\square$ menos de meia hora por dia

$\square$ meia hora por dia

$\square 1$ hora por dia

$\square 2$ horas por dia

$\square 3$ horas por dia

$\square 4$ ou mais horas por dia

$\square$ não sabe

65. Quantas pessoas moram na sua casa?

$\square 1$ pessoa

$\square 2$ pessoas

$\square 3$ pessoas

$\square 4$ pessoas

$\square 5$ pessoas

$\square 6$ pessoas

$\square 7$ pessoas

$\square 8$ pessoas

$\square 9$ pessoas

$\square 10$ ou mais pessoas

66. Quantos cômodos há na sua casa (conte os quartos, salas, copa e cozinha)?
$\square 1$ cômodo
$\square 2$ cômodos
口 3 cômodos
$\square 4$ cômodos
$\square 5$ cômodos
$\square 6$ cômodos
$\square 7$ cômodos
$\square 8$ cômodos
$\square 9$ cômodos
$\square 10$ ou mais cômodos

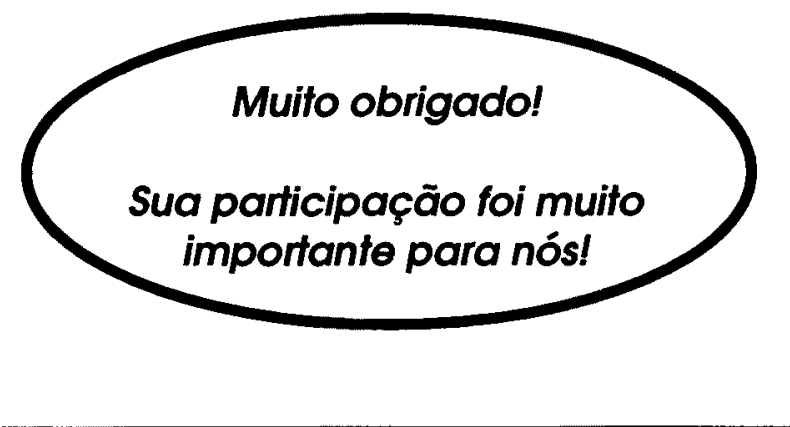


ANEXO 4 


\section{B tista}

São Paulo, 16 de fevereiro de 2004

Senhores pais,

O Colégio Batista Brasileiro comunica-lhes que foi selecionado para participar de uma pesquisa a se realizada pela nutricionista Renata Scanferla Siqueira da Faculdade de Saúde Pública da Universidade de São Paulo. Essa pesquisa objetiva avaliar o estado nutricional e os padrões de alimentação de estudantes da cidade de São Paulo.

A realização da pesquisa envolverá o preenchimento, pela família, do questionário que segue anexo, além da tomada de peso, altura e dobras cutâneas que é realizado na própria escola, conforme acontece a cada início do ano letivo. familia.

A participação de todos será de grande valia, porém de livre e espontânea vontade da

Atenciosamente,

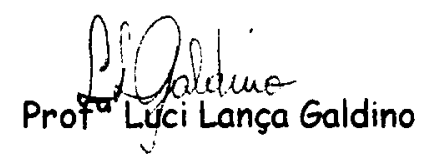

Coordenadora Pedagógica Geral 
ANEXO 5 
- LANCHES: os lanches são refeicões que merecem uma atencão especial, principalmente, quando são realizados fora de casa. Dê preferência a frutas, cereais, iogurtes, suco naturais, päes integrais, queijo branco, salgados assados

- BEBIDAS:Beba de 6 a 8 copos de água por dia. Refrigerantes são alimentos de baixo valor nutritivo, além de serem ricos em corantes e acidulantes artificiais. Estudos revelam que o consumo de refrigetantes e bebidas açucaradas está associado à obesidade em criancas e adolescentes. Dê preferência à água, água de coco, sucos de frutas e chás naturais, sempre adicionando o minimo de açucar refinado.

- MEXA-SE!! Procure alternativas para deixar o sedentarismo de lado! Pratique no minimo $30 \mathrm{~min}$. de atividade física diária, leve ou moderada, mantendo sempre uma freqüência.

Criancas e adolescentes que passam muitas horas do dia em frente à televisão e videogames têm maior risco de sobrepeso e obesidade.

- COMPRAS...Que tal um carrinho com alimentos mais saudáveis e nutritivos?Quando for às compras, escolfa produtos com baixo teor de gorduras e acucares, compre mais frutas e verduras, iogurte, cereais integrais ao invés de biscoitos recheados, doces e outras guloseimas. Esteja sempre atento ao rótulo dos alimentos..Adotando esse comportamento, você estará levando mais saúde e qualidade de vida para sua casa!

\section{Avaliação}

\section{Nutricional}

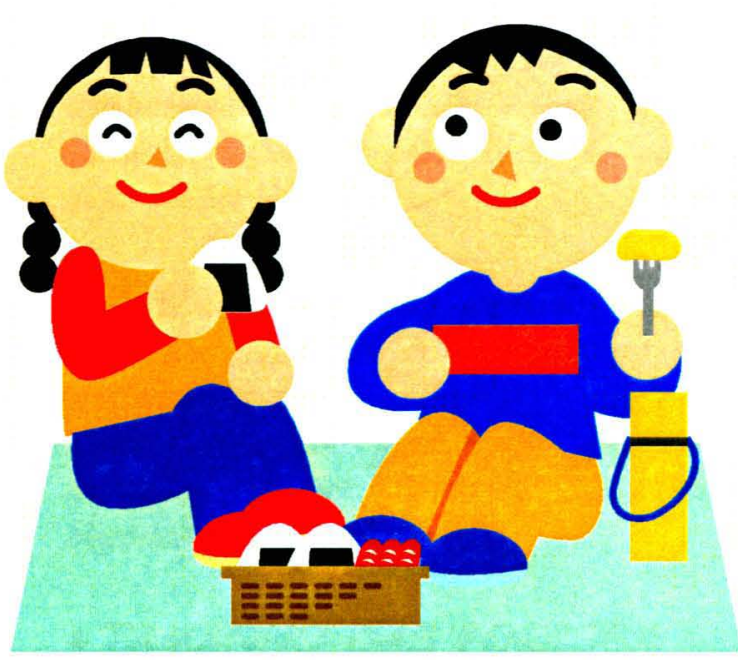

Colégio Batista Brasileiro

Elaborado por: RENATA SIQUEIRA

(nutricionista e pesquisadora da FSP-USP) IRENE COUTIN $\mathcal{N} O$

(nutricionista do Colégio Batista)
São Paulo

2004 
Prezados pais,

A nutrição adequada na infância e adolescência é importante para o crescimento e desenvolvimento de seu filfo(a), ao mesmo tempo em que se constitui num dos principais fatores de prevencão de algumas doenças (alteracões cardíacas e formonais, diabetes, dislipidemias, obesidades) tanto no decorrer da infância e adolescência quanto na idade adulta.

Bons fiábitos alimentares começam em casa e a escola também tem um importante papel.

Seja um bom exemplo para seu filho, faça escolhas saudáveis. Quando o ambiente favorece...fica muito mais fácil!!!

Obrigada pela sua participação!
Em resposta a avaliação nutricional de seu filko (a)

realizada no $1^{\circ}$ semestre/2004, segue a

sua classificação de acordo com critério da Organização Mundial de Saúde

(OMS, 1995) :

PESO: $k g$

ACTURA: $m$

\section{CLASSIFICAÇÃO DO ESTADO}

\section{NUTRICIONAL:}

$\square$ Eutrófico-peso e altura normais

$$
\text { plidade e sexo }
$$

$\square$ Baixo peso p/idade e sexo

$\square$ Risco para Sobrepeso

$\square$ Excesso de peso*

* para diagnóstico de excesso de peso, além de medidas de peso e altura, foram utilizados os valores de pregas cutâneas,

conforme recomendação da Organização Mundial de Saúde.
ALIMENTACÃO SAUDÁVEL E

\section{QUALIDADE DE VIDA}

- FRUTAS, Verduras e legumes. Consuma pelo menos 5 porcóes de frutas, legumes e verduras (400g) pois estes alimentos são pouco calóricos, contêm vitaminas $e$ minerais e fibras, além de não conterem gordura. Esta é uma recomendaça da OMS que esta baseada em estudos cientificos que já comprovaram que com esta atitude, podemos controlar melfhor o peso, além de prevenir algumas doencas.

-PREFIRA alimentos grelfados, cozidos assados e preparados sem gordura ou com o mínimo possivel.

Evite alimentos gordurosos, frituras $e$ enlatados, queijos amarelos, salgadinfos, biscoitos e doces.

- TAMANHO DAS PORCÕES: Sitva porçós pequenas e evite repetir. Coma devagar, mastigando bem os alimentos $e$ apreciando a refeicäo! № decorrer do dia, faça pelo menos 5 refeicooes (café da manhä, lanche, almoso, lanche da tarde e jantar), escolhendo sempre alimentos saudáveis.

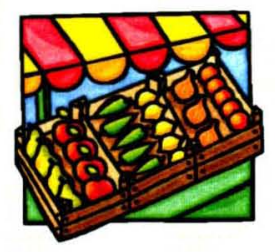

